\title{
Charity, Status, and Optimal Taxation: Welfarist and Non-Welfarist Approaches ${ }^{1}$
}

\author{
Thomas Aronsson a \\ Olof Johansson-Stenman b \\ Ronald Wendner $\mathrm{c}$ \\ a Department of Economics, Umeå School of Business, Economics and Statistics, Umeå \\ University, Sweden \\ $\mathrm{b}$ Department of Economics, School of Business, Economics and Law, University of \\ Gothenburg, Sweden \\ c Department of Economics, University of Graz, Austria
}

June 2021

\begin{abstract}
This paper analyzes optimal taxation of charitable giving to a public good in a Mirrleesian framework with social comparisons. Leisure separability together with zero transaction costs of giving imply that charitable giving should be subsidized to such an extent that governmental contributions are completely crowded out, regardless of whether the government acknowledges warm glows of giving. Stronger concerns for relative charitable giving and larger transaction costs support lower marginal subsidies, whereas relative consumption concerns work in the other direction. A dual screening approach, where charitable giving constitutes an indicator of wealth, is also presents. Numerical simulations supplement the theoretical results.
\end{abstract}

Keywords: Conspicuous consumption, conspicuous charitable giving, optimal taxation, public good provision, warm glow, multiple screening.

JEL Classification: D03, D62, H21, H23

\footnotetext{
${ }^{1}$ The authors would like to thank Tommy Andersson, Nathalie Bolh, Dawei Fang, David Granlund, Randi Hjalmarsson, Etienne Lehmann, Mikael Lindahl, Volker Meier, Katarina Nordblom, Tomas Sjögren, and Harald Uhlig for very helpful comments and suggestions. The paper has been presented at seminars at the University of Arizona, the Free University, Berlin, the University of Gothenburg, Linnaeus University, University of Osnabrück, Umeå University, and the University of Vermont, as well as at the 111th Annual Conference of the National Tax Association in New Orleans 2018, the 2019 Meeting of the of the European Public Choice Society in Jerusalem, and the 75th Annual Congress of the International Institute of Public Finance 2019 in Glasgow. The authors would like to thank the participants for valuable discussions. Research grants from The Marianne and Marcus Wallenberg Foundation (MMW 2015.0037) are gratefully acknowledged.
} 
What is the optimal tax treatment of charitable giving? Individuals and organizations donate substantial amounts to charities, not least in the United States where charitable giving amounted to about $\$ 450$ billion, or more than 2\% of GDP, in 2019 (Giving USA, 2020). The bulk of these donations can be described as voluntary contributions to public goods or community services, e.g., religious and environmental organizations and research, education, and public-society benefit charities (Giving USA, 2020). Thus, the importance of the above question is a given. The purpose of the present paper is to answer the question by integrating the tax treatment of charitable giving in a Mirrleesian model of optimal redistributive taxation. That the answer is non-trivial is indicated by the fact that tax policies related to charitable giving vary largely both between countries and within countries over time (Fack and Landais, 2012).

To our knowledge, the present study is the first to integrate voluntary contributions to a public good, to which there is also potential public provision, into a continuous-type Mirrleesian framework. In doing so, we also distinguish between a conventional welfarist government that respects all aspects of consumer preferences and forms the social objective thereupon, and a non-welfarist government that does not attach any social value to the warm glow of giving. Each such government collects revenue and redistributes through a nonlinear tax based on both gross income and charitable giving, implying that the set of available policy instruments reflects information limitations rather than a priori restrictions on the tax instruments. This is crucial and allows us to derive sharper and more easily interpretable policy rules than would otherwise be possible. For example, if the utility functions are weakly leisure separable (a common assumption in the optimal taxation literature), and in the absence of any transaction costs of charitable giving (as in previous literature; see below), a welfarist government would subsidize charitable contributions to such an extent that they completely crowd out governmental provision of the public good. The intuition is based on logic similar to the Atkinson and Stiglitz (1976) theorem: the marginal subsidies on charitable giving are in this case based on a first-best policy rule guided solely by concerns for economic efficiency. Such a policy favors charitable giving over public provision, since the former comes with the additional benefit of warm glow to the givers.

Even more strikingly, we show that this complete crowding-out result continues to hold also when the government is non-welfarist and does not attach any social value to the warm glow of giving. The logic here is that subsidizing charitable giving for high-income earners constitutes a cost-efficient means of redistribution. Furthermore, and regardless of whether the government values the warm glow of giving, the complete crowding out result 
remains if charitable giving and private consumption are driven by concerns for social status. We present sufficient conditions for complete crowding out in the general case where the utility functions are not necessarily leisure separable.

After a brief review of earlier research on the optimal tax treatment of voluntary contributions to public goods in Section I, Section II presents our Mirrleesian (1971) model using a modified version of Diamond's (1998) and Saez's (2001) ABC formulation, extended with private and public contributions to a public good. An important novelty is that we allow for transaction costs of charitable giving, such that a fraction of the contribution is lost in the process. Such costs play a critical role by reducing the marginal subsidies to charitable giving, and (if the costs are not too small) imply that the government should also contribute directly to the public good in accordance with a modified Samuelson rule. Under leisure separability, a welfarist government implements a flat rate subsidy on charitable giving, whereas a nonwelfarist government implements income-varying marginal subsidies.

Section III generalizes the model further to encompass conspicuous charitable giving and conspicuous consumption, respectively, such that people derive well-being from giving more to charity and consuming more than referent others, and vice versa., ${ }^{2,3}$ The model then contains three simultaneous externalities: i) A contribution to the public good by an individual increases the size of the public good and thus induces a corresponding benefit for all individuals. ii) The same contribution also decreases others' relative contribution, and correspondingly decreases their utility. iii) Increased consumption by an individual reduces the relative consumption of all others, and therefore decreases their utility. The strength of the concerns for relative charitable giving typically works in the direction of supporting lower marginal subsidies on charitable giving, whereas the strength of the concerns for relative consumption works in the other direction. An interesting exception arises if zero bunching in charitable giving is sufficiently prevalent, in which case an increase in the positional gifts externality may actually motivate a higher marginal subsidy (or a lower marginal tax) on

\footnotetext{
${ }^{2}$ Several studies suggest that charitable giving is a means of signaling status or prestige (e.g., Glazer and Konrad, 1996; Harbaugh, 1998).

${ }^{3}$ A large literature suggests that people derive well-being from their relative consumption or income. See, e.g., Johansson-Stenman et al. (2002), Solnick and Hemenway (2005), and Carlsson et al. (2007) for evidence based on questionnaire-experimental research, and Easterlin (2001), Blanchflower and Oswald (2004), Ferrer-iCarbonell (2005), and Clark and Senik (2010) for evidence based on happiness research. For theoretical work on tax and expenditure policy in the presence of relative income or consumption concerns, see, e.g., Boskin and Sheshinski (1978), Oswald (1983), Dupor and Liu (2003), Ljungqvist and Uhlig (2000), Aronsson and Johansson-Stenman (2008, 2010), Wendner and Goulder (2008), and Eckerstorfer and Wendner (2013).
} 
charitable giving. For governmental contributions to the public good and the marginal tax treatment of charitable giving, respectively, leisure separability simplifies the optimal policy rules dramatically, again based on logic similar to the Atkinson and Stiglitz (1976) theorem. In the general case where leisure separability no longer necessarily applies, we demonstrate how the redistributive components of these policy rules can be written directly in terms of the optimal marginal income tax. This way of writing the policy rules is novel and further emphasizes the roles of governmental provision to the public good and the marginal subsidy/tax on charity as supplemental instruments for income redistribution.

Section IV presents yet another generalization in the form of a dual screening model where individuals now differ in two dimensions: ability (gross wage), as before, and wealth, where wealth is also unobservable to the government and independent of the labor supplied. Assuming that charitable giving is a normal good, we use it as a second screening device in order to redistribute from individuals with higher ability and higher wealth. We express the optimal policy rules using a two-dimensional $\mathrm{ABC}$ formulation, where the positional externalities caused by concerns for relative consumption and relative charitable giving enter the policy rules in a way similar to the simpler model in Section III. However, since the logic behind the Atkinson-Stiglitz theorem is not applicable to the screening mechanism in the wealth dimension, leisure separability will no longer imply the same drastic simplifications of the policy rules.

Section $\mathrm{V}$ supplements the theoretical results with extensive numerical simulations based on specific functional forms for the utility functions and the ability distribution. Section VI concludes the paper, whereas proofs are presented in the Appendix.

\section{A Brief Literature Review on Optimal Taxation and Charitable Giving}

A number of studies have examined the policy implications of charitable giving in models of optimal (albeit not Mirrleesian) taxation, where the donations to charity are described in terms of voluntary contributions to a public good (e.g., Feldstein, 1980; Warr, 1982; Saez, 2004; Diamond, 2006; Blumkin and Sadka, 2007). ${ }^{4}$ In a model with optimal linear taxation, Saez (2004) shows that the optimal subsidy on voluntary contributions can be expressed as a sum of three elements: the positive externality that each contributor imposes on other people (as in

\footnotetext{
${ }^{4}$ There is also a much smaller literature modeling charitable giving as direct redistribution from richer to poorer groups; see Atkinson (1976), Kaplow (1995), and Aronsson, Johansson-Stenman, and Wendner (2019). Whereas the former two studies focus on the tax treatment of such gifts in a first-best environment, the latter examines optimal redistributive income taxation in a two-type model where the high-ability type can give an income transfer to the low-ability type.
} 
Warr, 1982), the price sensitivity of the contribution good, and the extent to which direct public contributions crowd out private contributions. Diamond (2006) uses a model of optimal nonlinear taxation developed by Diamond (1980), where the jobs available differ among skill types and the hours of work at a given job are fixed, to derive a second-best argument for marginal subsidies to charitable giving at the top of the income distribution. He shows that voluntary contributions by high earners relax the incentive compatibility constraint and hence motivate a marginal subsidy. In our Mirrleesian framework, the corresponding mechanisms can go in either direction (depending on whether the marginal valuation of charitable giving increases or decreases with the time spent on leisure) and would vanish under leisure separability.

Diamond (2006) also argues against using warm-glow preferences as a basis for social cost benefit analysis since the warm glow is likely to be context dependent. Furthermore, by recognizing warm glow as a source of benefit, there may also be reasons to devote resources to produce the contexts in which warm glow arises, which is not necessarily the best use of resources. Further arguments against including such benefits are related to the social pressure to contribute (e.g., DellaVigna et al., 2012). Yet, see Kaplow (1998) and Kaplow and Shavell (2001) for arguments suggesting that benefits arising from the warm glow of giving should indeed be accounted for. We therefore follow Diamond (2006) and present results reflecting both when the government values and when it does not value the warm glow of giving. ${ }^{5}$

Blumkin and Sadka (2007) examine a status motive for charitable giving as well as tax policy implications thereof. They consider a model where charitable donations signal status, while neglecting the warm-glow motive addressed by Saez and Diamond in their respective studies. By examining the welfare effect of introducing a small tax on charitable giving when the income tax is optimal, they find that the optimal tax on charitable giving is non-negative; it is positive if status concerns lead to overprovision of the public good compared with the Samuelson condition and zero otherwise. In the present paper, their finding can be seen as a special case.

\footnotetext{
${ }^{5}$ One could argue, e.g., based on Harsanyi (1982), that the government should not value relative consumption effects either; see Aronsson and Johansson-Stenman (2018) for implications in terms of optimal income taxation in a two-type model. The major qualitative results continue to hold for this extended version of non-welfarism, and are available from the authors upon request.
} 


\section{A Mirrleesian Model with Charitable Giving and Public Goods}

Consider an economy with linear production and competitive markets, implying that marginal productivity, $w$, reflects an ability-specific, fixed wage rate per unit of labor, which we refer to as ability in what follows. Ability is distributed continuously, and the population is fixed and normalized to one, i.e., $\int_{0}^{\infty} f(w) d w=1$. The size of the public good, $G$, depends on the sum of individual contributions, $g$, and the amount provided directly by the government, $G^{G o v}$.

Contrary to earlier studies on the optimal tax treatment of charitable contributions to public goods (see Section I), we introduce a transaction cost attached to charitable giving. We formalize this cost in a simple way by assuming a potential discrepancy between the donation and its contribution to the public good, such that the overall size of the public good is given as follows:

$$
G=G^{G o v}+(1-\mu) \int_{0}^{\infty} g_{w} f(w) d w,
$$

where $\mu<1$ thus reflects the transaction cost. Since there may be transaction costs also for governmental provision of public goods, it is natural to interpret $\mu$ as a measure of additional transaction costs associated with charitable giving. In this perspective, one cannot rule out that $\mu<0$. Yet, for simplicity, in the subsequent analysis we focus on the case where $\mu \geq 0$ (where interpretations thus change accordingly when $\mu<0$ ). One may also interpret $\mu$ more broadly as reflecting a less optimal distribution of public goods from society's point of view.

Individuals are endowed with one unit of time and supply $0 \leq l<1$ units of labor. Their utility depends on consumption, $c$, labor, $l$ (and hence leisure, $1-l$ ), and the overall level of the public good, $G$. In addition, it depends on their own charitable contribution to the public good, $g$, implying a corresponding warm glow (Andreoni, 1989): ${ }^{6}$

$$
u_{w}=u\left(c_{w}, l_{w}, g_{w}, G ; w\right) .
$$

We assume that $u(\cdot)$ is twice continuously differentiable, increasing in $c, g$, and $G$, decreasing in $l$, and strictly concave. ${ }^{7}$ We also assume that charitable giving is a normal good. Following, e.g., Saez (2004) and Blumkin and Sadka (2007), individuals are assumed to be

\footnotetext{
${ }^{6}$ This should not be interpreted to mean that people solely care about how much they contribute and not about the public good to which they contribute. Thus, if we were to extend the model to include several public goods, which is quite straightforward, the warm glow per dollar contributed may differ among charities.

${ }^{7}$ Alternatively, one may assume that people derive utility from their net contribution to the public good, $(1-\mu) g$. Since $\mu$ is exogenous to the individual, we can still think of equation (2) as a reduced form. All qualitative insights would hold also with this alternative formulation.
} 
atomistic agents by treating the level of the public good, $G$, as exogenous. ${ }^{8}$ In Section III, we make the analogous assumption that individuals treat externalities as exogenous. The final argument in the utility function reflects that we allow for continuous preference heterogeneity. The preferences may be very different for, say, individuals at the $75^{\text {th }}$ percentile of the income distribution compared with those at the $25^{\text {th }}$ percentile, but the preference differences are small for small differences in ability and vanish completely without any ability differences. For later use, the following definition will prove useful:

Definition. The utility function is denoted leisure separable if it can be written $u_{w}=V\left(k\left(c_{w}, g_{w}, G ; w\right), l_{w} ; w\right)$.

Leisure separability thus implies that the marginal rates of substitution between $c, G$, and $g$ are independent of labor (and hence leisure) for all individuals. Note that this assumption is weaker than additive separability, which is often assumed (see e.g., Tuomala, 2016). The individual budget constraint implies that the sum of private consumption and charitable giving equals gross income, $y=w l$, minus the taxes paid:

$$
y_{w}-T\left(y_{w}, g_{w}\right)=c_{w}+g_{w},
$$

where $T(y, g)$ is a general, nonlinear tax function through which the tax payment depends on both gross income and charitable giving. Each individual chooses consumption, work hours, and charitable giving to maximize utility given by (2) subject to their respective budget constraint (3). In addition to (3), an interior solution satisfies the individual first-order conditions for labor supply and charitable giving:

$$
M R S_{l, c}^{(w)} \equiv \frac{u_{l}^{(w)}}{u_{c}^{(w)}}=-w\left(1-T_{y}^{(w)}\right) ; M R S_{g, c}^{(w)} \equiv \frac{u_{g}^{(w)}}{u_{c}^{(w)}}=1+T_{g}^{(w)} .
$$

Single subscripts attached to the utility function or tax function reflect partial derivatives (unless being $w$ ), where $T_{y}$ denotes the marginal income tax and $T_{g}$ the marginal tax or subsidy (if negative) on charitable giving; $(w)$ refers to ability type.

The social welfare function is a generalized utilitarian welfare function as follows:

$$
W=\int_{0}^{\infty} \psi\left(u_{w}\right) f(w) d w,
$$

\footnotetext{
${ }^{8}$ This is in contrast to Bergstrom, Blume, and Varian (1986), where individuals treat $G$ as endogenous. In their study, an individual's contribution is not negligible to $G$.
} 
where $\psi$ is (weakly) concave. We will consider two versions of social welfare: a conventional welfarist objective where the government takes individual utility at face value (as in [5]) and a non-welfarist version where the government does not value utility changes caused by the warm glow of giving. Whether the government is welfarist or not, it faces the same resource constraint and incentive compatibility constraints. The resource constraint means that the aggregate production equals the sum of aggregate private consumption and charitable giving plus the governmental contributions to the public good,

$$
\int_{0}^{\infty} w l_{w} f(w) d w=\int_{0}^{\infty}\left(c_{w}+g_{w}\right) f(w) d w+G^{G o v} .
$$

We assume that the government observes income and charitable giving at the individual level, whereas ability is private information. The incentive compatibility constraints serve to prevent individuals of any type $w$ from mimicking the ability type just below them in terms of observable income and charitable giving,

$$
d u_{w} / d w=-l_{w} u_{l}^{(w)} / w .
$$

Our tax instruments and informational assumptions imply that the government can implement any desired combination of labor supply, consumption, and charitable giving for each type subject to the resource and incentive compatibility constraints. Therefore, we follow much earlier work in formulating the social decision problem as a direct decision problem throughout the paper. In doing so, we treat utility, $u_{w}$, as a state variable, while $l_{w}, g_{w}$, and $G^{G o v}$ are control variables. Consumption, $c_{w}$, is defined by the inverse of the function $u(\cdot)$ in equation (2) such that $c_{w}=h\left(l_{w}, g_{w}, G, u_{w} ; w\right)$, the properties of which are $h_{l}^{(w)}=-M R S_{l, c}^{(w)}$, $h_{g}^{(w)}=-M R S_{g, c}^{(w)}, h_{G}^{(w)}=-M R S_{G, c}^{(w)} \equiv-u_{G}^{(w)} / u_{c}^{(w)}$, and $h_{u}^{(w)}=1 / u_{c}^{(w)}$, where a subscript attached to the function $h(\cdot)$ denotes a partial derivative. The policy rules for marginal income taxation and the marginal subsidization/taxation of charitable giving can then be derived by combining the private and social first-order conditions; thus, following convention in the optimal taxation literature, we implicitly assume that underlying convexity assumptions are fulfilled to ensure that the second-order conditions for a unique social optimum hold.

\section{A. Welfarist Government}

The welfarist government maximizes the social welfare function (5) subject to (6), (7), and the non-negativity constraint $G^{G o v} \geq 0 .{ }^{9}$ The non-negativity constraint on governmental

\footnotetext{
${ }^{9} \mathrm{We}$ choose not to include non-negativity constraints on charitable giving here. If individuals do not engage in social comparisons with respect to charitable giving, such non-negativity constraints do not affect the policy rule
} 
contributions plays an important role for the marginal tax treatment of charitable giving. Let $\varepsilon_{l}^{l c}=\left(\partial M R S_{l, c} / \partial l\right)\left(l / M R S_{l, c}\right)$ represent the elasticity of $M R S_{l, c}$ with respect to $l$ and let $\delta_{w}=\psi^{\prime}\left(u_{w}\right) u_{c}^{(w)} / \lambda$ denote the welfare weight attached to type $w$, where $\lambda$ is the Lagrange multiplier on the resource constraint. Following Diamond's (1998) ABC formulation, we can then define ${ }^{10}$

$$
\begin{aligned}
& A_{w}=1+\varepsilon_{l(w)}^{l c}, \\
& B_{w}=\int_{w}^{\infty}\left(1-\delta_{w}\right) \exp \left(-\int_{w}^{s} \frac{\partial M R S_{l c}^{(m)}}{\partial c} \frac{d y_{m}}{m}\right) \exp \left(-\int_{w}^{s} \frac{\partial M R S_{g c}^{(m)}}{\partial c} d g_{m}\right) \frac{f(s)}{1-F(w)} d s, \\
& C_{w}=\frac{1-F(w)}{w f(w)} .
\end{aligned}
$$

Equations (8a)-(8c) are the building blocks of the policy rule for marginal income taxation and will be interpreted below. To simplify the presentation, let $\varepsilon_{l}^{G c}=\left(\partial M R S_{G, c} / \partial l\right)\left(l / M R S_{G, c}\right)$ and $\varepsilon_{l}^{g c}=\left(\partial M R S_{g, c} / \partial l\right)\left(l / M R S_{g, c}\right)$ represent the elasticities of $M R S_{G, c}$ and $M R S_{g, c}$ with respect to labor, and let $S^{0}$ denote society's net marginal cost of public good provision in the absence of any direct contribution to the public good by the government (to be formalized below). We can now summarize the optimal policy rules for marginal income taxation, governmental provision of the public good, and the marginal tax treatment of charitable giving (where $(w)$ as subscript or superscript reflects dependency on $w$ ). In order to simplify presentation and the corresponding interpretations, we start with the special case of leisure separability and then present the results for the general non-separable case. ${ }^{11}$

underlying the optimal tax treatment of charitable giving. We introduce non-negativity constraints in Section III, where individuals derive well-being from their relative charitable giving.

${ }^{10}$ Under leisure separability, we can express $A$ in the same way as Saez (2001) so $A=1+\varepsilon_{l}^{l c}=\left(1+\varsigma^{u}\right) / \varsigma^{c}$, where $\varsigma^{u}$ and $\varsigma^{c}$ are the uncompensated and compensated elasticity, respectively, of $l$ with respect to the marginal wage rate derived under a linearized budget constraint. Under quasi-linearity, as in Diamond (1998), (8b) simplifies to $B_{w}=\int_{w}^{\infty}\left(1-\delta_{w}\right) f(s) /(1-F(w)) d s$.

${ }^{11}$ The marginal income tax rates in (i) apply for those supplying labor (as in e.g. Saez 2001), and the marginal subsidies/taxes on charitable giving in (ii) and (iii) apply for those contributing to charity. In the numerical simulations, we address zero-bunching both in terms of work hours and charitable giving, and also illustrate the income ranges where people contribute to charity and where they do not. 
Proposition 1a. For a welfarist government, and if the utility functions are leisure separable, (i)-(iv) hold:

(i) $\frac{T_{y}^{(w)}}{1-T_{y}^{(w)}}=A_{w} B_{w} C_{w}$.

(ii) If $G^{G o v}>0$, then $\int_{0}^{\infty} M R S_{G, c}^{(w)} f(w) d w=1$ and $T_{g}^{(w)}=-1+\mu$.

(iii) If $G^{G o v}=0$, then $T_{g}^{(w)}=-1+\mu+(1-\mu) S^{0}$.

(iv) If $\mu=0$, then $G^{\text {Gov }}=0$.

The $\mathrm{ABC}$ rule for marginal income taxation in (i) and the policy rule for public good provision in (ii), where the marginal rate of transformation between public and private goods is equal to one, take the same general forms as in the absence of any charitable giving, although $B$ is modified with an additional income effect in the $g$-dimension. The variable $A$ is interpretable as an efficiency mechanism based on behavioral responses, $B$ reflects the desire for redistribution, and $C$ reflects the thickness of the upper tail of the ability distribution. Based on logic similar to the Atkinson-Stiglitz (1976) theorem, the policy rule for public good provision reduces to the standard Samuelson condition under leisure separability, as in the seminal contributions by Christiansen (1981) and Boadway and Keen (1993), both of which are based on models without private contributions to the public good.

The policy rules for $T_{g}$ in results (ii) and (iii) of the proposition refer to the marginal tax treatment of charitable giving, i.e., the main interest of the present paper. Consider first the special case without any transaction costs $(\mu=0)$, which is the case examined in all existing literature dealing with tax policy implications of charitable giving. Then, if $G^{G o v}>0$, (ii) would imply $T_{g}=-1$, i.e., a $100 \%$ marginal subsidy to charitable giving. Obviously, such a policy mix cannot be optimal, since utility increases monotonically in charitable giving. Instead, this special case implies $G^{G o v}=0$ according to (iv). (Note that the condition in [iv], $\mu=0$, is sufficient but not necessary for $G^{G o v}=0$.) Thus, it is optimal for the government not to contribute at all to the public good! The intuition is that charitable giving provides an additional welfare benefit due to the warm glow of giving that does not follow from governmental provision. The policy rule for the marginal subsidy to charitable giving is then correspondingly modified and given in (iii), where

$$
S^{0}=1-\left(\int_{0}^{\infty} M R S_{G, c}^{(w)} f(w) d w\right)_{G^{G o v}=0} \geq 0
$$

measures the discrepancy between society's marginal cost and marginal benefit of governmental provision evaluated at $G^{G o v}=0$. In technical terms, $S^{0}$ is the Lagrange 
multiplier of the non-negativity constraint for $G^{\text {Gov }}$ over the Lagrange multiplier of the resource constraint. ${ }^{12}$ Thus, the government reduces the marginal subsidy in order to try to avoid that voluntary contributions lead to overprovision of the public good relative to the Samuelson condition, and it does so by choosing $T_{g}^{(w)}=-1+S^{0}$ for all $w$ when $\mu=0$.

It is interesting to compare this policy rule with a corresponding result by Saez (2004), who derives optimal linear income and charitable giving taxation. Such a comparison is complicated by the fact that the linearity restriction (in addition to the other constraints) typically requires additional simplifying assumptions to obtain policy rules comparable with those derived under nonlinear taxation. When Saez makes a number of additional assumptions, ${ }^{13}$ he finds that the tax rate on charitable giving is equal to -1 , i.e., a $100 \%$ subsidy; thus, there is no additional $S^{0}$ term, as in our case. Yet, we can resolve this puzzle by noting that Saez does not explicitly assume utility to be monotonically increasing (as we do), but only non-decreasing, in charitable giving. Therefore, it is possible to interpret the extreme $100 \%$ subsidy as resulting from a situation where the marginal utility of charitable giving equals zero beyond a certain level of giving. This opens up for the possibility that the voluntary contributions are small enough to imply that direct governmental provision would still be optimal. ${ }^{14}$ Consequently, the non-negativity constraint for governmental provision does not bind in this case, and a $100 \%$ subsidy rate would be perfectly logical. The same result would follow in our model. Moreover, if utility would be monotonically increasing in charitable giving in the model by Saez, the policy rule $-1+S^{0}$ would result there as well. ${ }^{15}$

\footnotetext{
${ }^{12}$ See the Appendix for details.

${ }^{13}$ Specifically: i) there are no income effects on earnings, ii) the aggregate gross income is independent of both the public good and the subsidy on charitable giving, iii) the compensated supply of contributions does not depend on the income tax, and iv) the aggregate voluntary contribution is reduced by exactly one unit for each additional unit of governmental provision. The results in the present paper, in contrast, hold regardless of whether these assumptions are fulfilled or not.

${ }^{14}$ However, when individuals are indifferent about whether or not to contribute more to the public good (despite a $100 \%$ subsidy), the individual optimization problem does not have a unique solution. For the latter we would also need an additional assumption that all individuals prefer not to contribute more in this situation.

15 The first-order condition for governmental provision of the public good is given by equation (5) in Saez (2004), which assumes that this contribution is positive. By adding the assumption that utility is monotonically increasing (instead of non-decreasing) in charitable giving, and explicitly recognizing the non-negativity constraint on governmental contributions, it is straightforward to use Saez's model to show that the subsidy to charitable giving becomes $-1+S^{0}$, where $S^{0}$ is given by the Lagrange multiplier of the non-negativity constraint over the Lagrange multiplier of the resource constraint.
} 
Proposition 1a also implies that if $\mu>0$ and sufficiently large, the governmental contribution to the public good is positive and the marginal subsidy attached to charitable giving is based on the policy rule in (ii). It is also immediately obvious from (ii) and (iii) that leisure separability implies that the marginal subsidy on charitable giving is the same for all contributors. Thus, contrary to the marginal income tax rate that typically varies with the gross income, the optimal marginal subsidy on charitable giving is in this case independent of gross income (and also of the individual's contribution).

Finally, and again by analogy to the Atkinson-Stiglitz (1976) theorem, leisure separability means that the policy rule for $T_{g}$ takes the same form as in a first-best setting without informational asymmetries. In other words, the marginal tax treatment of charitable giving is guided by economic efficiency, while redistribution is dealt with through the income tax.

If the utility functions are not leisure separable, the policy rules for $G^{G o v}$ and $T_{g}$ in Proposition 1a no longer apply. Proposition $1 \mathrm{~b}$ presents the results for the general case, which also includes non-separable preferences:

Proposition 1b. For a welfarist government, (i)-(iv) hold:

(i) $\frac{T_{y}^{(w)}}{1-T_{y}^{(w)}}=A_{w} B_{w} C_{w}$.

(ii) If $G^{\text {Gov }}>0$, then

$$
\begin{aligned}
& \int_{0}^{\infty} M R S_{G, c}^{(w)}\left(1+\varepsilon_{l(w)}^{G c} B_{w} C_{w}\right) f(w) d w=\int_{0}^{\infty} M R S_{G, c}^{(w)}\left(1+\frac{\varepsilon_{l(w)}^{G c}}{1+\varepsilon_{l(w)}^{l c}} \frac{T_{y}^{(w)}}{1-T_{y}^{(w)}}\right) f(w) d w=1, \\
& T_{g}^{(w)}=-1+\mu-\varepsilon_{l(w)}^{g c} M R S_{g, c}^{(w)} B_{w} C_{w}=-1+\mu-M R S_{g, c}^{(w)} \frac{\varepsilon_{l(w)}^{g c}}{1+\varepsilon_{l(w)}^{l c}} \frac{T_{y}^{(w)}}{1-T_{y}^{(w)}} .
\end{aligned}
$$

(iii) If $G^{\text {Gov }}=0$, then

$$
T_{g}^{(w)}=-1+\mu+(1-\mu) S^{0}-\varepsilon_{l(w)}^{g c} M R S_{g, c}^{(w)} B_{w} C_{w}=-1+\mu+(1-\mu) S^{0}-M R S_{g, c}^{(w)} \frac{\varepsilon_{l(w)}^{g c}}{1+\varepsilon_{l(w)}^{l c}} \frac{T_{y}^{(w)}}{1-T_{y}^{(w)}} .
$$

(iv) If $\mu=0$ and $\varepsilon_{l(w)}^{g c} \geq 0$ for some $w$ for which $g_{w}>0$, then $G^{G o v}=0$.

The policy rule for the marginal income tax remains the same as under leisure separability (although the values of the $A B C$-factors will of course vary with respect to underlying assumptions). However, the policy rules for $G^{G o v}$ and $T_{g}$ in (ii) and (iii) differ from their counterparts in Proposition 1a through terms proportional to the behavioral elasticities $\varepsilon_{l}^{G c}$ and $\varepsilon_{l}^{g c}$, respectively. These additional components arise because the public good and the marginal subsidy/tax on charitable giving now supplement the income tax as instruments for 
income redistribution, which explains the interaction between the behavioral elasticities and the product $B C$. To further emphasize how $G^{G o v}$ and $T_{g}$ interact with the marginal income tax policy, in the expression after the second equality we present a second variant of each such policy rule where the behavioral elasticity is proportional to $T_{y} /\left(1-T_{y}\right)$. Thus, the absolute value of this redistributive component increases with the marginal income tax rate, ceteris paribus. Another implication of relaxing the separability assumption is that the marginal subsidy/tax on charitable giving typically varies with the before-tax income (which it did not under leisure separability).

The last term on the right-hand side of (both versions of) the policy rule for $T_{g}$ in (ii) reflects the government's incentive to relax the incentive compatibility constraints by exploiting how individuals' marginal valuation of charitable giving varies with leisure time for a given disposable income (which was ruled out under leisure separability). If $\varepsilon_{l}^{g c}<0$, charitable giving becomes more valuable relative to consumption when leisure increases (labor decreases). Due to the conventional tax wedge, people have incentives to consume too much (untaxed) leisure, meaning that the government has an incentive to subsidize charitable giving at a lower marginal rate, and vice versa if $\varepsilon_{l}^{g c}>0$.

The policy rule for $T_{g}$ in (iii), where $G^{G o v}=0$ at the second-best optimum, extends in the same general way (compared with the leisure-separable case in Proposition 1a). The factor reflecting the discrepancy between society's marginal cost and marginal benefit of public good provision, $S^{0}$, will correspondingly be modified due to non-separability (and can be written in terms of either the $B C$ product or the marginal income tax) as follows:

$$
S^{0}=1-\left(\int_{0}^{\infty} M R S_{G, c}^{(w)}\left(1+\varepsilon_{l(w)}^{G c} B_{w} C_{w}\right) f(w) d w\right)_{G^{G o v}=0}=1-\left(\int_{0}^{\infty} M R S_{G, c}^{(w)}\left(1+\frac{\varepsilon_{l(w)}^{G c}}{1+\varepsilon_{l(w)}^{l c}} \frac{T_{y}^{(w)}}{1-T_{y}^{(w)}}\right) f(w) d w\right)_{G^{G o v}=0} \geq 0 .
$$

Result (iv) in Proposition $1 \mathrm{~b}$ focuses on the case where $\mu=0$ and generalizes (iv) in Proposition 1a (where $\varepsilon_{l(w)}^{g c}=0$ for all $w$ due to leisure separability). In the absence of any transaction costs, a sufficient condition for $G^{G o v}=0$ is that $\varepsilon_{l(w)}^{g c} \geq 0$ for some $w$ for which $g_{w}>0$; hence, $\varepsilon_{l(w)}^{g c} \geq 0$ need not hold for all $w$. The intuition is that if individuals for whom $\varepsilon_{l(w)}^{g c} \geq 0$ can be made to contribute one more unit of the public good, there will be an additional positive social net benefit compared with a one unit provision by the government. ${ }^{16}$

\footnotetext{
${ }^{16}$ Result (iv) gives a sufficient (not necessary) condition here as well. Note that increased charitable giving by type $w$ leads to a relaxation (tightening) of the incentive compatibility constraint for this type if $\varepsilon_{l(w)}^{g c}>0(<0)$.
} 
We can also see that the relaxation of the separability assumption leads to a similar modification of the policy rule for governmental provision in (ii), where the additional term depends on how the marginal willingness to pay for the public good varies with leisure time. While this general insight is well known, see, e.g., Christiansen (1981) and Boadway and Keen (1993), we are not aware of any previous formulation of the policy rule for public good provision expressed in terms of either the $B C$ factor or the optimal marginal income tax.

Taken together, the redistributive elements of the policy rules for $G^{G o v}$ and $T_{g}$, which reflect their usefulness as instruments for relaxation of the incentive compatibility constraints, can be written in terms of estimable elasticities $\left(\varepsilon_{l}^{G c}, \varepsilon_{l}^{g c}\right.$, and $\left.\varepsilon_{l}^{l c}\right)$ and the marginal income tax rates. In particular, note that the higher the marginal income tax rates, the greater the influence of these elements in the policy rules, ceteris paribus. This is intuitive: the higher the marginal income tax rates, the more costly the redistributive income tax policy, and the greater the need to use $G^{G o v}$ and $T_{g}$ as supplemental instruments for redistribution.

\section{B. Non-Welfarist Government}

The non-welfarist government would like individuals to behave as if they do not derive wellbeing from the warm glow of giving. Consequently, the government imposes a "laundered" utility function on each individual of any ability $w$,

$$
u_{w}^{n}=u\left(c_{w}, l_{w}, \overline{g_{w}}, G ; w\right)=v\left(c_{w}, l_{w}, G ; w\right),
$$

where the non-welfarist government treats charitable giving as exogenous and attaches no social value to changes in warm glow; yet, in equilibrium we have $\overline{g_{w}}=g_{w}$, meaning that (2) and (9) take the same value. Therefore, the social welfare function in equation (5) is now replaced with

$$
W^{n}=\int_{0}^{\infty} \psi\left(u_{w}^{n}\right) f(w) d w .
$$

Compared with the welfarist model examined above, the optimal control problem is modified in the sense that (10) replaces (5), and (9) appears as an additional Lagrange constraint. Thus,

Thus, it would actually suffice to assume that there are contributing individuals for whom $\varepsilon_{l(w)}^{g c}$ is either nonnegative or sufficiently small in absolute value, such that the welfare effect through the incentive compatibility constraint, if negative, is not large enough to outweigh the positive welfare effect through the warm glow of giving. Corresponding remarks can be made on subsequent results concerning zero public provision, i.e., result (iii) of Proposition $2 \mathrm{~b}$ and result (iv) of Proposition $3 \mathrm{~b}$. 
$u_{w}^{n}$ is treated as an additional state variable here (see also the Appendix). The remaining constraints are the same as in the welfarist model, since the true utility functions still drive individual behavior.

The policy rules for marginal income taxation and governmental public good provision are the same as in the welfarist case, but the marginal tax treatment of charitable giving now changes. We will again for presentational reasons start with the leisure-separable case. Let $\varepsilon_{c(w)}^{\delta}=-\left(\partial \delta_{w} / \partial c_{w}\right)\left(c_{w} / \delta_{w}\right)$ represent the (negative of the) elasticity of the welfare weight with respect to consumption, ${ }^{17}$ and let $\varepsilon_{c(w)}^{g c}=\left(\partial M R S_{g, c}^{(w)} / \partial c_{w}\right)\left(c_{w} / M R S_{g, c}^{(w)}\right)$ denote the elasticity of the marginal willingness to pay for warm glow with respect to consumption. We can then present the following results:

Proposition 2a. For a non-welfarist government, and if the utility functions are leisure separable, $(i)-(i v)$ hold:

(i) If $G^{G o v}>0$, then $T_{g}^{(w)}=-1+\mu+\delta_{w} M_{R} S_{g, c}^{(w)}$.

(ii) If $G^{G o v}=0$, then $T_{g}^{(w)}=-1+\mu+(1-\mu) S^{0}+\delta_{w} M R S_{g, c}^{(w)}$.

(iii) For $g_{w}>0, T_{g}^{(w)}$ satisfies $\partial T_{g}^{(w)} / \partial y_{w}>0(<0)$ iff $\varepsilon_{c(w)}^{\delta}>(<) \varepsilon_{c(w)}^{g c}$.

(iv) If $\mu=0$, then $G^{G o v}=0$.

The policy rules presented in (i) and (ii) of Proposition 2a differ from their counterparts in the welfarist case, Proposition 1a, due to the appearance of the last term on the right-hand side (i.e., the component proportional to $\delta_{w}$ ). This component appears because individuals value the warm glow of giving while the government does not, meaning that the government will adjust the incentive structure accordingly. The welfare weight $\delta_{w}$ reflects that redistribution is costly, and that it is socially preferable for this reason that high-income individuals rather than low-income individuals contribute to charity.

This additional component in the policy rule also explains (iii) in the proposition, since leisure separability (where $\varepsilon_{l}^{g c}=0$ ) implies that all marginal tax components are constant except this final term. Thus, contrary to the corresponding policy rule under welfarism, the marginal subsidy on charitable giving typically varies with gross income here: the marginal subsidy increases in the gross income (and thus in the disposable income and ability) if $\varepsilon_{c(w)}^{\delta}>\varepsilon_{c(w)}^{g c}$, and vice versa. Consider the special case with a utilitarian social

\footnotetext{
${ }^{17}$ For example, in the utilitarian case, $\varepsilon_{c(w)}^{\delta}$ would reflect the curvature of the cardinal utility function, as measured by the coefficient of relative risk aversion.
} 
welfare function where $\varepsilon_{c(w)}^{\delta}$ reflects the curvature of the cardinal utility function, as measured by the coefficient of relative risk aversion (or the elasticity of the marginal utility of consumption). Let us also assume that utility varies logarithmically with consumption, corresponding to a constant coefficient of relative risk aversion equal to one. Then the optimal marginal subsidy increases with income if $\varepsilon_{c(w)}^{g c}>1$ (and vice versa), i.e., if the marginal willingness to pay for warm glow increases more than proportionally with private consumption; this case is illustrated numerically in Figure 1, Section V.

That result (iv), which implies complete crowing out of governmental provision under zero transaction costs and leisure separability, holds also in the non-welfarist case may seem surprising at first thought, since the non-welfarist government attaches no social value to warm glow. In addition, leisure separability eliminates all welfare effects of charitable giving related to the incentive compatibility constraints (as it also did in the welfarist case). However, there are distributional reasons for the non-welfarist government to prefer charitable giving to public contributions. In this case, there is a social net cost if low-income people $\left(\delta_{w}>1\right)$ contribute and a social net benefit if high-income people $\left(\delta_{w}<1\right)$ do. By combining the marginal tax/subsidy rule for charitable giving with the private first-order condition, it is easy to see that only individuals for whom $\delta_{w}<1$ will contribute at the optimum and thus generate welfare gains in terms of a lower social cost of redistribution, while there are no corresponding benefits from governmental provision. Proposition $2 \mathrm{~b}$ presents the results for the general utility function (2), which does not assume leisure separability:

Proposition 2b. For a non-welfarist government, (i)-(iii) hold:

(i) If $G^{\text {Gov }}>0$, then

$$
\begin{aligned}
T_{g}^{(w)} & =-1+\mu+\delta_{w} M R S_{g, c}^{(w)}-\varepsilon_{l(w)}^{g c} M R S_{g, c}^{(w)} B_{w} C_{w} \\
& =-1+\mu+\delta_{w} M R S_{g, c}^{(w)}-M R S_{g, c}^{(w)} \frac{\varepsilon_{l(w)}^{g c}}{1+\varepsilon_{l(w)}^{l c}} \frac{T_{y}^{(w)}}{1-T_{y}^{(w)}} .
\end{aligned}
$$

(ii) If $G^{\text {Gov }}=0$, then

$$
\begin{aligned}
T_{g}^{(w)} & =-1+\mu+(1-\mu) S^{0}+\delta_{w} M R S_{g, c}^{(w)}-\varepsilon_{l(w)}^{g c} M R S_{g, c}^{(w)} B_{w} C_{w} \\
& =-1+\mu+(1-\mu) S^{0}+\delta_{w} M R S_{g, c}^{(w)}-M R S_{g, c}^{(w)} \frac{\varepsilon_{l(w)}^{g c}}{1+\varepsilon_{l(w)}^{l c}} \frac{T_{y}^{(w)}}{1-T_{y}^{(w)}}
\end{aligned}
$$

(iii) If $\mu=0$ and $\varepsilon_{l(w)}^{g c} \geq 0$ for some $w$ for which $g_{w}>0$, then $G^{G o v}=0$.

We observe from results (i) and (ii) that the modifications due to non-separable utility take the same form as under welfarism. Thus, also under non-welfarism, if $\varepsilon_{l}^{g c}<0(>0)$, such that 
charitable giving becomes more (less) valuable relative to consumption when leisure increases, ceteris paribus, the government has an incentive to subsidize charitable giving at a lower (higher) marginal rate. By analogy to the marginal tax treatment of charitable giving under welfarism, we can write the new redistributive component of the policy rule for $T_{g}$ in terms of either the $B C$ factors or the marginal income tax rates.

The condition for when zero governmental provision of the public good is optimal, given in result (iii), generalizes to the same condition as in Proposition 1b. The intuition follows by combining the reasoning behind Propositions $1 \mathrm{~b}$ and 2a. Essentially, if individuals for whom $\varepsilon_{l(w)}^{g c} \geq 0$ can be made to contribute one more unit of the public good, there will be an additional social net benefit compared with governmental provision. This is because the social cost of redistribution through charitable giving is lower than through a corresponding, and tax funded, increase in $G^{\text {Gov }}$.

\section{Incorporating Preferences for Relative Giving and Relative Consumption}

In Section II, we made the conventional assumption that utility depends only on the individual's own consumption and charitable giving (in addition to leisure time and the public good). We will now assume that individuals also derive well-being from their relative consumption and relative charitable giving. This means that individuals impose positional externalities on one another. Following the bulk of earlier research on optimal taxation and relative consumption, we start with the most common comparison form, the mean-value comparison, which in our case means that individuals compare their own consumption with the average consumption and their own charitable giving with the average charitable giving. At the end of this section, we discuss some alternative comparison forms and the implications thereof.

\section{A. The model}

Extending the utility function to accommodate relative consumption and relative charitable giving, equation (2) is now replaced with

$$
u_{w}=v\left(c_{w}, l_{w}, g_{w}, \Delta c_{w}, \Delta g_{w}, G ; w\right)=u\left(c_{w}, l_{w}, g_{w}, \bar{c}, \bar{g}, G ; w\right),
$$

where $\Delta c_{w}=c_{w}-\bar{c}$ denotes the relative consumption and $\Delta g_{w}=g_{w}-\bar{g}$ the relative charitable giving of an individual of type $w$, while $\bar{c}$ denotes the average consumption and $\bar{g}$ the average charitable giving in the economy as a whole, i.e.,

$$
\bar{c}=\int_{0}^{\infty} c_{w} f(w) d w \text { and } \bar{g}=\int_{0}^{\infty} g_{w} f(w) d w .
$$


The function $v(\cdot)$ in (11) is increasing in $c, g$, and $G$, non-decreasing in $\Delta c$ and $\Delta g$, decreasing in $l$, and strictly concave, while the function $u(\cdot)$ is now interpretable as a reduced form, which will be used in some of the calculations presented below. We summarize the relationships between $v(\cdot)$ and $u(\cdot)$ as follows: $u_{c}=v_{c}+v_{\Delta c}, u_{l}=v_{l}, u_{g}=v_{g}+v_{\Delta g}, u_{G}=v_{G}$, $u_{\bar{c}}=-v_{\Delta c}$, and $u_{\bar{g}}=-v_{\Delta g}$, where subscripts denote partial derivatives. ${ }^{18}$ As above, we assume that charitable giving is a normal good. Each individual behaves as an atomistic agent and treats $G, \bar{c}$, and $\bar{g}$ as exogenous. The individual first-order conditions in (4) continue to hold, where the MRS expressions are defined in terms of the function $u(\cdot)$. Leisure separability is correspondingly defined such that the utility function can be written

$$
u_{w}=V\left(k\left(c_{w}, g_{w}, c_{w}-\bar{c}, g_{w}-\bar{g}, G ; w\right), l_{w} ; w\right) .
$$

Let us now introduce measures of the importance of relative consumption and relative charitable giving. Following Johansson-Stenman et al. (2002), the degree of consumption positionality, $\alpha \equiv v_{\Delta c} /\left(v_{c}+v_{\Delta c}\right) \in[0,1)$, reflects the share of the marginal utility of consumption arising from an increase in $\Delta c$. Similarly, the degree of charitable positionality, $\beta \equiv v_{\Delta g} /\left(v_{g}+v_{\Delta g}\right) \in[0,1)$, is the share of the marginal utility of charitable giving that arises from an increase in $\Delta g$. In general, these measures vary across individuals and the corresponding average degrees of positionality are given by

$$
\bar{\alpha}=\int_{0}^{\infty} \alpha_{w} f(w) d w \text { and } \bar{\beta}=\int_{0}^{\infty} \beta_{w} f(w) d w .
$$

We can interpret each such average degree as the sum of all individuals' marginal willingness to pay to avoid the corresponding externality. ${ }^{19}$

In addition to the average degrees of positionality, the relationship between each degree of positionality and the labor supply is important for tax policy and public good provision. This is because the government can exploit these relationships in order to relax the incentive compatibility constraints. Let $\varepsilon_{l}^{\alpha}=(\partial \alpha / \partial l) /(\alpha / l)$ denote the elasticity of the

\footnotetext{
${ }^{18}$ Using the language of Dupor and Liu (2003), the properties $u_{\bar{c}}=-v_{\Delta c}<0$ and $u_{\bar{g}}=-v_{\Delta g}<0$ can be referred to as "jealousy."

${ }^{19}$ Quasi-experimental research estimates $\bar{\alpha}$ to be in the 0.2-0.6 range (see, e.g., Johansson-Stenman et al., 2002; Clark and Senik, 2010; Carlsson et al., 2007; and the overview by Wendner and Goulder, 2008). We are not aware of any empirical estimate of $\bar{\beta}$. However, clearly visible goods are characterized by higher degrees of positionality than less visible goods (e.g., Alpizar et al., 2005; Carlsson et al., 2007). Harbaugh (1998) argues that the prestige motive in charitable giving is likely to be empirically important in the sense that "a substantial portion of donations can be attributed to it" (p. 281).
} 
degree of consumption positionality with respect to labor supply, and let $\varepsilon_{l}^{\beta}=(\partial \beta / \partial l) /(\beta / l)$ denote the corresponding labor supply elasticity of the degree of charitable positionality. We can then define the following indicators of how the concerns for relative consumption and relative charitable giving affect the incentive compatibility constraints, which will be part of the policy rules presented below:

$$
\begin{aligned}
& \alpha^{d}=\int_{0}^{\infty} \varepsilon_{l(w)}^{\alpha} \alpha_{w} B_{w} C_{w} f(w) d w \\
& \beta^{d}=\int_{0}^{\infty} \varepsilon_{l(w)}^{\beta} M R S_{g, c}^{(w)} \beta_{w} B_{w} C_{w} f(w) d w .
\end{aligned}
$$

Note the type-specific $B C$ component in (14a) and (14b), connecting the redistributive aspects of positional externalities to the $A B C$ rule for optimal taxation. The variables $A$ and $C$ are defined as in (8a) and (8c), whereas the definition of $B$ changes slightly as the positional consumption externality affects the cost of redistribution,

$$
B_{w}=\int_{w}^{\infty}\left(\frac{1+\alpha^{d}}{1-\bar{\alpha}}-\delta_{w}\right) \exp \left(-\int_{w}^{s} \frac{\partial M R S_{l c}^{(m)}}{\partial c} \frac{d y_{m}}{m}\right) \exp \left(-\int_{w}^{s} \frac{\partial M R S_{g c}^{(m)}}{\partial c} d g_{m}\right) \frac{f(s)}{1-F(w)} d s .
$$

The welfarist government maximizes social welfare function (5), where $u_{w}$ is now given by (11), subject to resource and incentive compatibility constraints analogous to equations (6) and (7), the externality constraints (12), and the non-negativity constraint $G^{G o v} \geq 0$ on direct public contribution. We also impose non-negativity constraints on charitable giving, $g_{w} \geq 0$ for all w. Although these constraints played no role for tax policy in Section II (and were consequently omitted), they are important here. The reason is that concerns for relative charitable giving among the non-contributors will influence the marginal tax treatment of charitable giving. For later use, let $\phi_{w}$ denote the Lagrange multiplier attached to the nonnegativity constraint for $g$ on type $w$.

The non-welfarist government solves a similar decision problem, albeit with two important modifications. First, the non-welfarist government does not respect the individual preferences for charitable giving, neither in absolute nor in relative terms, and therefore imposes a laundered utility function on each individual, which is given as follows for any type $w$ :

$$
u_{w}^{n}=v\left(c_{w}, l_{w}, \overline{g_{w}}, \Delta c_{w}, \overline{\Delta g_{w}}, G ; w\right)=v\left(c_{w}, l_{w}, \bar{c}, G ; w\right) .
$$

During optimization, the non-welfarist government thus treats the absolute and relative charitable giving as exogenous. Yet, in equilibrium we have $\overline{g_{w}}=g_{w}$ and $\overline{\Delta g_{w}}=\Delta g_{w}$, meaning 
that equations (11) and (16) take the same value. Second, under non-welfarism, $u_{w}^{n}$ replaces $u_{w}$ for all $w$ in the social welfare function.

The social decision problems faced by the welfarist and non-welfarist governments are solved in the same way as in Section II with the modification that $\bar{c}$ and $\bar{g}$ are now added to the set of control variables (which also includes $l_{w}, g_{w}$, and $G$ ). Thus, individual consumption is now defined by the inverse of the $u(\cdot)$ function in (11) instead of in (2), such that $c_{w}=h\left(l_{w}, g_{w}, G, \bar{c}, \bar{g}, u_{w} ; w\right)$, where the properties with respect to $l_{w}, g_{w}, G$, and $u_{w}$ are analogous to those described in Section 3, while the properties with respect to $\bar{c}$ and $\bar{g}$ are summarized by $h_{\bar{c}}^{(w)}=-u_{\bar{c}}^{(w)} / u_{c}^{(w)}=\alpha_{w}$ and $h_{\bar{g}}^{(w)}=-u_{\bar{g}}^{(w)} / u_{c}^{(w)}=\beta_{w} M R S_{g, c}^{(w)}$.

\section{B. The optimal policy rules under social comparisons}

Since the policy rules used by the welfarist and non-welfarist governments are similar in many ways, it is convenient to present them in the same propositions. To facilitate the presentation and interpretations, we start with the special case where the utility functions are leisure separable, as we also did in Section II. Let $N$ be an indicator variable, such that $N=0$ under welfarism and $N=1$ under non-welfarism, and let $\beta^{\text {non }}>0$ denote the decrease in the positional gifts externality caused by bunching at zero charitable giving (to be made more precise below). Consider Proposition 3a.

Proposition 3a. Under social comparisons, and if the utility functions are leisure separable, (i)-(iv) hold for welfarist and non-welfarist governments:

$$
\frac{T_{y}^{(w)}}{1-T_{y}^{(w)}}=A_{w} B_{w} C_{w}+\frac{\bar{\alpha}}{1-\bar{\alpha}} .
$$

(ii) If $G^{G o v}>0$, then

$$
\begin{aligned}
& \int_{0}^{\infty} \frac{M R S_{G, c}^{(w)}}{1-\bar{\alpha}} f(w) d w=1 \\
& T_{g}^{(w)}=-1+N \delta_{w}(1-\bar{\alpha}) M R S_{g, c}^{(w)}+\frac{1-\bar{\alpha}}{1-\bar{\beta}}\left(\mu-\beta^{n o n}\right) .
\end{aligned}
$$

(iii) If $G^{G o v}=0$, then

$$
T_{g}^{(w)}=-1+N \delta_{w}(1-\bar{\alpha}) M R S_{g, c}^{(w)}+\frac{1-\bar{\alpha}}{1-\bar{\beta}}\left(\mu+(1-\mu) S^{0}-\beta^{n o n}\right) .
$$

(iv) If $\mu=0$, then $G^{\text {Gov }}=0$.

(v) For a non-welfarist government, $T_{g}^{(w)}$ satisfies $\partial T_{g}^{(w)} / \partial y_{w}>(<) 0$ iff $\varepsilon_{c(w)}^{\delta}<(>) \varepsilon_{c(w)}^{g c}$.

Results (i) and (ii) show how the positional consumption externality modifies the policy rules for marginal income taxation and public good provision. As such, they generalize the policy 
rules presented by Aronsson and Johansson-Stenman (2008) for a two-type model without charitable giving. In a first-best setting where individual productivity is observable, which is equivalent to the special case of our model where the incentive compatibility constraints do not bind, the policy rule in (i) reduces to $T_{y}^{(w)}=\bar{\alpha}$, which is a conventional Pigouvian tax reflecting the marginal willingness to pay to avoid the positional consumption externality. In a second-best world with information asymmetries, this Pigouvian element is combined with the $A B C$ component. Therefore, the positional consumption externality leads to an additional, additive term in the policy rule reflecting the corrective motive for marginal income taxation. Correspondingly, the public good formula is modified to reflect that the private and social marginal willingness to pay measures for public goods differ under positional consumption externalities. More specifically, the private marginal willingness to pay, $M R S_{G, c}$, underestimates the social marginal willingness to pay if $\bar{\alpha}>0$.

Turning to the marginal taxation/subsidization of charitable giving, some of the main results presented in Section II (such as [iv] of Proposition 1a and [iii] and [iv] of Proposition 2a) carry over in a natural way to Proposition 3a. In particular, the complete crowding out of governmental public good provision under leisure separability and zero transaction costs holds here as well, regardless of type of government. Whether or not the government directly contributes to the public good plays the same role for the marginal tax/subsidy treatment of charitable giving as it did in Section II. The variable $S^{0}$, which adjusts the policy rule for $T_{g}$ when $G^{G o v}=0$, is now slightly modified to reflect the positional consumption externality, i.e.,

$$
S^{0}=1-\left(\int_{0}^{\infty} \frac{M R S_{G, c}^{(w)}}{1-\bar{\alpha}} f(w) d w\right)_{G^{G o v}=0} \geq 0 .
$$

There are three important differences between the policy rules for $T_{g}$ presented here and the simpler policy rules in Propositions 1a and 2a. First, the transaction cost, $\mu$, is now multiplied by the factor $(1-\bar{\alpha}) /(1-\bar{\beta})$, reflecting the ratio of the degrees of non-positionality between private consumption and charitable giving. $\mu(1-\bar{\alpha}) /(1-\bar{\beta})$ is then interpretable in terms of a corresponding social transaction cost. Second, if the optimal resource allocation implies bunching in that some individuals should not contribute to charity (which is typically the case), the positional externality attributable to charitable giving will be smaller than otherwise. The intuition is that a small decrease in $\bar{g}$ cannot be accompanied by decreased charitable giving among non-contributors (this adjustment is only feasible for the 
contributors), meaning that the average degree of charitable positionality, $\bar{\beta}$, overestimates the corresponding welfare benefit. The variable

$$
\beta^{\text {non }}=\int_{0}^{w^{0}}\left(\beta_{w} \phi_{w} / \lambda\right) d w
$$

reflects society's valuation of this discrepancy, where $w^{0}$ denotes the type with the highest productivity that does not contribute to the public good. This adjustment also implies that an increase in $\bar{\beta}$ may actually result in a higher marginal subsidy to charitable giving. This occurs for a sufficiently small $\mu$ combined with a sufficiently large fraction of noncontributors, resulting in a high $\beta^{\text {non }}$, as shown in one of the numerical simulations in Section $\mathrm{V}$. Third, in the non-welfarist case, the second term on the right hand side of the policy rules for $T_{g}$, i.e.,

$$
(1-\bar{\alpha}) \delta_{w} M R S_{g, c}^{(w)} \equiv(1-\bar{\alpha}) \delta_{w} \frac{u_{g}^{(w)}}{u_{c}^{(w)}}=(1-\bar{\alpha}) \delta_{w} \frac{v_{g}^{(w)}+v_{\Delta g}^{(w)}}{v_{c}^{(w)}+v_{\Delta c}^{(w)}},
$$

now reflects the warm glow to the individuals of both absolute and relative charitable giving. Thus, both aspects of the warm glow of giving contribute to decrease the marginal subsidy (or increase the marginal tax) on charitable giving. Note also that the factor $1-\bar{\alpha}$ serves to take into account that decreased charitable giving comes at the cost of an increase in the positional consumption externality. The latter motivates a smaller increase in $T_{g}$ in order to correct for the behavioral failure than in the absence of any consumer preference for relative consumption, ceteris paribus.

Finally, results (ii), (iii), and (v) show that the welfarist government continues to subsidize charitable giving at a flat rate under leisure separability, and that the same pattern as before regarding income-dependency of the marginal subsidy continues to hold under nonwelfarism, also in the presence of relative concerns.

While the policy rules in Proposition $3 \mathrm{a}$ assume that the utility functions take the leisure separable form in (16), Proposition $3 b$ presents the corresponding results for the general utility functions in (11):

Proposition 3b. Under social comparisons, (i)-(iv) hold for welfarist and non-welfarist governments:

(i) $\quad \frac{T_{y}^{(w)}}{1-T_{y}^{(w)}}=A_{w} B_{w} C_{w}+\frac{\bar{\alpha}+\alpha^{d}}{1-\bar{\alpha}}$.

(ii) If $G^{G o v}>0$, then 


$$
\begin{aligned}
& \int_{0}^{\infty} M R S_{G, c}^{(w)}\left(\frac{1+\alpha^{d}}{1-\bar{\alpha}}+\varepsilon_{l}^{G c} B_{w} C_{w}\right) f(w) d w=1, \text { and } \\
& T_{g}^{(w)}=-1+\frac{1-\bar{\alpha}}{1+\alpha^{d}}\left(N \delta_{w}-\varepsilon_{l(w)}^{g c} B_{w} C_{w}\right) M R S_{g, c}^{(w)}+\frac{1-\bar{\alpha}}{1-\bar{\beta}} \frac{\mu+\beta^{d}-\beta^{n o n}}{1+\alpha^{d}} .
\end{aligned}
$$

(iii) If $G^{G o v}=0$, then

$$
T_{g}^{(w)}=-1+\frac{1-\bar{\alpha}}{1+\alpha^{d}}\left(N \delta_{w}-\varepsilon_{l(w)}^{g c} B_{w} C_{w}\right) M R S_{g, c}^{(w)}+\frac{1-\bar{\alpha}}{1-\bar{\beta}} \frac{\mu+(1-\mu) S^{0}+\beta^{d}-\beta^{n o n}}{1+\alpha^{d}} .
$$

(iv) If $\mu=0, \beta^{n o n} \geq \beta^{d}$, and $\alpha^{d}>-1$, and if $\varepsilon_{l(w)}^{g c} \geq 0$ for some $w$ for which $g_{w}>0$, then $G^{\text {Gov }}=0$.

Note first that the elasticities $\varepsilon_{l}^{G c}$ and $\varepsilon_{l}^{g c}$ in the policy rules for $G^{G o v}$ and $T_{g}$ are interpretable in the same way as in the simpler model in Section II. ${ }^{20}$ The only difference is that the product $B C$ is no longer directly proportional to the marginal income tax wedge (see below). Note also that the conditions for when it is optimal to have zero governmental provision of the public good, presented in result (iv), are similar to those in Propositions $1 b$ and $2 b$, and the intuition is also essentially the same. The additional conditions $\beta^{n o n} \geq \beta^{d}$ and $\alpha^{d}>-1$ imposed here ensure that the welfare cost of increased charitable giving through a potential tightening of the incentive compatiability constraints never dominates the warm glow benefit. In an economy with a relatively large fraction of non-contributors (which is typically the case according to our numerical simulations), these two conditions are not very restrictive. Thus, also under non-separability, in the presence of relative comparisons, and regardless of whether the government is welfarist or non-welfarist, zero transaction costs together with rather mild additional assumptions ${ }^{21}$ ensure that it is optimal for the government not to directly contribute to the public good, but to rely on private voluntary contributions.

${ }^{20}$ The variable $S^{0}$ in the expression for $T_{g}$ in result (iii) is now based on the policy rule for public good provision in (ii) of Proposition $3 \mathrm{~b}$ and given as follows:

$$
S^{0}=1-\left(\int_{0}^{\infty} M R S_{(w)}^{G c}\left(\frac{1+\alpha^{d}}{1-\bar{\alpha}}+\varepsilon_{l(w)}^{G c} B_{w} C_{w}\right) f(w) d w\right)_{G^{G o v}=0} \geq 0 .
$$

${ }^{21}$ As we show in the Appendix, the even less restrictive assumption that there exists some $w$ such that

$$
\varepsilon_{l(w)}^{g c} \frac{1-\bar{\alpha}}{1+\alpha^{d}} B_{w} C_{w} M R S_{g, c}^{(w)}+\frac{1-\bar{\alpha}}{1-\bar{\beta}} \frac{\beta^{n o n}-\beta^{d}}{1+\alpha^{d}}>0
$$

in equilibrium is sufficient in the welfarist case. In the non-welfarist case, sufficiency follows from

$$
\operatorname{MRS}_{g, c}^{(w)}\left(1-\delta_{w} \frac{1-\bar{\alpha}}{1+\alpha^{d}}\right)+\varepsilon_{l(w)}^{g c} \frac{1-\bar{\alpha}}{1+\alpha^{d}} B_{w} C_{w} M R S_{g, c}^{(w)}+\frac{1-\bar{\alpha}}{1-\bar{\beta}} \frac{\beta^{n o n}-\beta^{d}}{1+\alpha^{d}}>0 \text { for some } w .
$$


Result (i) differs from its counterpart in Proposition 3a through the variable $\alpha^{d}$, which is present because correction for the positional consumption externality will now have a role in redistribution; cf. (14a). If $\varepsilon_{l}^{\alpha}<0$, individuals with more leisure time suffer more from the positional consumption externality than individuals who spend less time on leisure, ceteris paribus. This means from (14) that $\alpha^{d}<0$, such that the government can relax the incentive compatibility constraints by a policy-induced increase in $\bar{c}$. This motivates a lower marginal income tax. Through similar mechanisms, $\varepsilon_{l}^{\alpha}<0$ also motivates a smaller governmental contribution to the public good and a lower marginal subsidy (or higher marginal tax) on charitable giving than otherwise. Policy implications opposite to those just described arise if $\varepsilon_{l}^{\alpha}>0$.

The variable $\beta^{d}$, see $(14 \mathrm{~b})$, in the policy rule for $T_{g}$ can be interpreted in a similar way. If $\varepsilon_{l}^{\beta}<0$, individuals with more leisure time suffer more than individuals with less leisure time from the positional gifts externality, ceteris paribus, implying that $\beta^{d}<0$. Therefore, the government can relax the incentive compatibility constraints through a policyinduced increase in $\bar{g}$, which motivates a higher marginal subsidy (or lower marginal tax) on charitable giving than otherwise, and vice versa if $\beta^{d}>0$.

The usefulness of $\bar{c}$ and $\bar{g}$ as means of relaxing the incentive compatibility constraints, and consequently the importance of $\alpha^{d}$ and $\beta^{d}$ for the marginal tax treatment of charitable giving, depends on how positional people are, how the degrees of positionality vary with the labor supply, and on the product $B C$. This product is now interpretable in terms of the non-corrective component of the marginal income tax, which follows directly from (i), i.e.,

$$
B_{w} C_{w}=\frac{1}{1+\varepsilon_{l}^{l c(w)}}\left(\frac{T_{y}^{(w)}}{1-T_{y}^{(w)}}-\frac{\bar{\alpha}+\alpha^{d}}{1-\bar{\alpha}}\right) .
$$

The $B C$ component is proportional to the difference between the marginal income tax wedge and the marginal social value of the positional consumption externality. As such, the product $B C$ is still interpretable in terms of a tax distortion (as in the model without relative concerns examined in Section II), since the corrective tax component is subtracted away. Thus, the more distortive the income tax, the more important the other channels of redistribution will be.

\section{Briefly on alternative measures of reference consumption and reference giving}

The mean-value comparison form examined above is the standard assumption in research on optimal taxation and relative consumption. We have examined the policy implications of two 
alternative comparison forms, both of which result in non-atmospheric externalities. ${ }^{22}$ One is the within-type comparison, where each individual compares their own consumption and charitable giving with those of individuals of the same ability type. Choosing it can be justified based on the idea that individuals may in particular compare their own behavior with that of similar others (e.g., Runciman, 1966). Equations (12) can then be replaced with the following type-specific externality constraints:

$$
\bar{c}_{w}=c_{w} \text { and } \bar{g}_{w}=g_{w} \text {. }
$$

Let $\alpha_{w}^{d}=\varepsilon_{l(w)}^{\alpha} \alpha_{w} B_{w} C_{w}$ and $\beta_{w}^{d}=\varepsilon_{l(w)}^{\beta} \beta_{w} B_{w} C_{w}$ be type-specific indicators of how the degrees of consumption positionality and charitable positionality vary with labor supply (or leisure time), ceteris paribus. These variables will now replace $\alpha^{d}$ and $\beta^{d}$ in Proposition $3 \mathrm{~b}$, which are defined in equations (14a) and (14b). As above, $N$ is an indicator such that $N=1$ under nonwelfarism and $N=0$ under welfarism. Irrespective of whether the government is welfarist or non-welfarist, the policy rules for marginal income taxation and governmental provision in Proposition $3 b$ change to read

$$
\begin{aligned}
& \frac{T_{y}^{(w)}}{1-T_{y}^{(w)}}=A_{w} B_{w} C_{w}+\frac{\alpha_{w}+\alpha_{w}^{d}}{1-\alpha_{w}}, \\
& \int_{0}^{\infty} M R S_{G, c}^{(w)}\left(\frac{1+\alpha_{w}^{d}}{1-\alpha_{w}}+\varepsilon_{l}^{G c} B_{w} C_{w}\right) f(w) d w=1, \text { if } G^{G o v}>0 .
\end{aligned}
$$

Similarly, the marginal tax treatment of charitable giving obeys the following policy rules for $G^{G o v}>0$ and $G^{G o v}=0$, respectively, at the social optimum:

$$
\begin{aligned}
& T_{g}^{(w)}=-1+\frac{1-\alpha_{w}}{1+\alpha_{w}^{d}}\left(N \delta_{w}-\varepsilon_{l(w)}^{g c} B_{w} C_{w}\right) M R S_{g, c}^{(w)}+\frac{1-\alpha_{w}}{1-\beta_{w}} \frac{\mu+\beta_{w}^{d}}{1+\alpha_{w}^{d}} \\
& T_{g}^{(w)}=-1+\frac{1-\alpha_{w}}{1+\alpha_{w}^{d}}\left(N \delta_{w}-\varepsilon_{l(w)}^{g c} B_{w} C_{w}\right) M R S_{g, c}^{(w)}+\frac{1-\alpha_{w}}{1-\beta_{w}} \frac{\mu+(1-\mu) S^{0}+\beta_{w}^{d}}{1+\alpha_{w}^{d}}
\end{aligned}
$$

where $S^{0}$ is now related to the generalized Samuelson condition in (18b), i.e.,

$$
S^{0}=1-\left(\int_{0}^{\infty} M R S_{G, c}^{(w)}\left(\frac{1+\alpha_{w}^{d}}{1-\alpha_{w}}+\varepsilon_{l}^{G c} B_{w} C_{w}\right) f(w) d w\right)_{G^{G o v}=0} .
$$

Therefore, the policy rules derived under within-type comparisons are very similar to those presented in Proposition 3b, with the only exceptions being that the average degrees of positionality are replaced with type-specific degrees and that zero-bunching in charitable giving has no direct consequences for the policy rule underlying the marginal subsidy/tax on

\footnotetext{
22 The calculations are available from the authors upon request.
} 
charitable giving. The reason is, in both cases, that the externalities generated by within-type comparisons are type specific, such that the reference measures for consumption and charitable giving differ between types. Thus, (18c) and (18d) imply type-specific marginal taxation of charitable giving under welfarism regardless of whether the preferences are leisure separable. All other interpretations are the same as in the previous subsection.

The other comparison form is a generalized mean-value comparison, implying that $\bar{c}$ and $\bar{g}$ are replaced with general weighted averages, $c^{R}$ and $g^{R}$, such that the externality constraints become

$$
c^{R}=\int_{0}^{\infty} c_{w} \kappa_{w} f(w) d w \text { and } g^{R}=\int_{0}^{\infty} g_{w} m_{w} f(w) d w,
$$

where $\kappa_{w}$ and $m_{w}$ reflect the relative weights of type $w$ in the reference measures. Each such relative weight sums to unity over the population as a whole,

$$
\int_{0}^{\infty} \kappa_{w} f(w) d w=\int_{0}^{\infty} m_{w} f(w) d w=1 .
$$

Thus, if the marginal contribution to the externality by each type is proportional to the number of persons of this type, then $\kappa_{w}=m_{w}=1$ for all $w$. In general, however, $\kappa_{w}$ and $m_{w}$ will vary among types. This comparison form encompasses the case where most individuals compare upward, as suggested already by Veblen (1899), which in our case means that $\kappa_{w}$ and $m_{w}$ increase in ability. Although the generalized mean-value comparison implies slightly more complex policy rules than under mean-value comparisons, most qualitative conclusions and interpretations presented above continue to hold here as well. Let

$$
\hat{\alpha}=\int_{0}^{\infty} \alpha_{w} \kappa_{w} f(w) d w \text { and } \hat{\beta}=\int_{0}^{\infty} \beta_{w} m_{w} f(w) d w
$$

denote "contribution-weighted averages" of the degrees of consumption positionality and charitable positionality, respectively. The following policy rules for marginal income taxation and governmental provision will now replace the policy rules in Proposition $3 \mathrm{~b}$ (regardless of whether the government is welfarist or non-welfarist):

$$
\begin{aligned}
& \frac{T_{y}}{1-T_{y}}=A_{w} B_{w} C_{w}+\kappa_{w} \frac{\bar{\alpha}+\alpha^{d}}{1-\hat{\alpha}} \\
& \int_{0}^{\infty} M R S_{G, c}^{(w)}\left(\frac{1+\bar{\alpha}-\hat{\alpha}-\alpha^{d}}{1-\hat{\alpha}}+\varepsilon_{l}^{G c} B_{w} C_{w}\right) f(w) d w=1, \text { if } G^{G o v}>0 .
\end{aligned}
$$

There are two differences between these policy rules in (20) and those in Proposition 3b. First, type $w$ 's relative weight in the reference measure is now proportional to the externality 
component in (20a), emphasizing that non-atmospheric externalities necessitate type-specific corrections. Second, the variable $\hat{\alpha}$ appears because an increase or decrease in $c^{R}$ feeds back into the consumption behavior. In turn, this leads to additional effects on the externality, which depend on how the associated changes in consumption interact with the relative weights in the reference measure. In the special case examined in the previous subsection where the externality is atmospheric, $\hat{\alpha}=\bar{\alpha}$.

The marginal tax treatment of charitable giving obeys the following policy rule under generalized mean-value comparisons if $G^{G o v}>0$ at the social optimum (which now replaces the policy rule in [ii] of Proposition 3b):

$$
\begin{aligned}
T_{g}= & -1+\frac{1-\hat{\alpha}}{1-\hat{\alpha}+\left(\bar{\alpha}+\alpha^{d}\right) \kappa_{w}}\left(N \delta_{w} M R S_{g, c}-\varepsilon_{l(w)}^{g c} M R S_{g, c}^{(w)} B_{w} C_{w}\right) \\
& +\frac{1-\hat{\alpha}}{1-\hat{\alpha}+\left(\bar{\alpha}+\alpha^{d}\right) \kappa_{w}} \frac{\mu \bar{\beta}+\beta^{d}-\beta^{n o n}}{(1-\hat{\beta})} m_{w}+\mu
\end{aligned} .
$$

Equation (20c) coincides with the policy rule for $T_{g}$ in (ii) of Proposition $3 \mathrm{~b}$ in the special case where the externalities are atmospheric, which means that $\kappa_{w}=m_{w}=1$ for all $w, \hat{\alpha}=\bar{\alpha}$, and $\hat{\beta}=\bar{\beta}$. In a way similar to within-type comparisons, albeit in contrast to mean-value comparisons, (20c) implies that the marginal subsidy/tax on charitable giving varies among types under welfarism even if the preferences are leisure separable. This is because the positional externalities associated with generalized mean-value comparisons are nonatmospheric. By analogy to the analyses above, if $G^{G o v}=0$ at the social optimum, a term proportional to $S^{0}$ will be added to the right-hand side of equation (26c), where $S^{0}$ now reflects (20b) such that

$$
S^{0}=1-\left(\int_{0}^{\infty} M R S_{G, c}^{(w)}\left(\frac{1+\bar{\alpha}-\hat{\alpha}-\alpha^{d}}{1-\hat{\alpha}}+\varepsilon_{l}^{G c} B_{w} C_{w}\right) f(w) d w\right)_{G^{G o v}=0} .
$$

In summary, the policy implications of within-type comparisons and generalized mean-value comparisons are reminiscent of those following from mean-value comparisons. The structure of the policy rules is qualitatively very similar in all three cases. Therefore, the conclusion is that the main policy implications of relative concerns presented in Propositions $3 \mathrm{a}$ and $3 \mathrm{~b}$ carry over to the other two comparison forms. The most important exception arises in the special case where the preferences are leisure separable, where a welfarist government would subsidize charitable giving at a flat rate under mean-value comparisons, while the marginal subsidy rate varies among types under the other two comparison forms. 


\section{A Dual Screening Approach to Optimal Taxation and Charitable Giving}

So far, we have assumed that individuals differ in productivity, measured by the before-tax wage rate, and that the preferences may vary between types but are identical for individuals of the same productivity. Drawing on Cremer et al. (2001), we will here present a model in which individuals differ in two dimensions: the before-tax wage rate $(w)$, as above, and exogenous wealth $(b)$, where wealth is also unobservable to the government and independent of labor supplied. The preferences may correspondingly differ in both dimensions. Since charitable giving is assumed to be a normal good, we are able to use it as a second screening device, in order to redistribute from individuals with higher ability and higher wealth. Ability and wealth then follow a joint distribution with density $f(w, b)$. The analytical approach is largely based on Renes and Zoutman (2017) and Lehmann et al. (2020). ${ }^{23}$

The utility function facing any individual of type $(w, b)$ can then be written as

$$
u_{w, b}=v\left(c_{w, b}, l_{w, b}, g_{w, b}, \Delta c_{w, b}, \Delta g_{w, b}, G ; w, b\right)=u\left(c_{w, b}, l_{w, b}, g_{w, b}, \bar{c}, \bar{g}, G ; w, b\right) \text {, }
$$

where $\Delta c_{w, b}=c_{w, b}-\bar{c}$ and $\Delta g_{w, b}=g_{w, b}-\bar{g}$. Equation (21) has the same properties as equation (11). In addition, we assume that leisure is a normal good and that the marginal willingness to pay for the public good increases in income. The special case of leisure separability discussed below is the same as before. It means that (21) simplifies to

$$
u_{w, b}=V\left(k\left(c_{w, b}, g_{w, b}, c_{w, b}-\bar{c}, g_{w, b}-\bar{g}, G ; w, b\right), l_{w, b} ; w, b\right) .
$$

As in most of Section III, we assume that the relative concerns are driven by mean-value comparisons, where the average consumption and average charitable giving can now be written as

$$
\bar{c}=\int_{0}^{\infty} \int_{0}^{\infty} c_{w, b} f(w, b) d w d b \text { and } \bar{g}=\int_{0}^{\infty} \int_{0}^{\infty} g_{w, b} f(w, b) d w d b,
$$

respectively. The individual budget constraint is now

$$
w l_{w, b}-T\left(w l_{w, b}, g_{w, b}\right)+b=c_{w, b}+g_{w, b},
$$

where a wealth term, $b$, is added to net labor income. Note that since wealth is unobserved by the government, so is consumption for a given net income. Yet, the individual first-order conditions for labor and charitable giving are still given by (4).

The welfarist government still maximizes a generalized utilitarian social welfare function

$$
W=\int_{0}^{\infty} \int_{0}^{\infty} \psi\left(u_{w, b}\right) f(w, b) d w d b
$$

\footnotetext{
${ }^{23}$ For important earlier contributions to the literature on optimal taxation under multiple screening, see Mirrlees (1986), Kleven et al. (2009), and Golosov et al. (2014).
} 
subject to a resource constraint

$$
\int_{0}^{\infty} \int_{0}^{\infty} w l_{w, b} f(w, b) d w d b=\int_{0}^{\infty} \int_{0}^{\infty}\left(c_{w, b}+g_{w, b}\right) f(w, b) d w d b+G^{G o v},
$$

and, now a two-dimensional, incentive compatibility constraint

$$
\frac{d u_{w, b}}{d w}=-\frac{l_{w, b} u_{l}^{(w, b)}}{w}, \quad \text { and } \quad \frac{d u_{w, b}}{d b}=u_{c}^{(w, b)}
$$

Thus, the government maximizes social welfare function (24), where $u_{w, b}$ is given by (21), subject to resource constraint (25), incentive compatibility constraints (26), externality constraints (22), and non-negativity constraints $G^{G o v} \geq 0$ and $g_{w, b} \geq 0$ for all $w$ and $b$.

In the non-welfarist case we add the "laundered" utility function that the government attaches to each type, which takes the same form as equation (16), i.e.,

$$
u_{w, b}^{n}=v\left(c_{w, b}, l_{w, b}, \overline{g_{w, b}}, \Delta c_{w, b}, \overline{\Delta g_{w, b}}, G ; w, b\right)=v\left(c_{w, b}, l_{w, b}, \bar{c}, G ; w, b\right) .
$$

By analogy to Section III, $\overline{g_{w, b}}=g_{w, b}$ and $\overline{\Delta g_{w, b}}=\Delta g_{w, b}$ in equilibrium, meaning that equations (21) and (27) take the same value. During optimization, the non-welfarist government treats the absolute and relative charitable giving as exogenous. Also, $u_{w, b}^{n}$ replaces $u_{w, b}$ in the social welfare function such that equation (24) is now replaced with

$$
W^{n}=\int_{0}^{\infty} \int_{0}^{\infty} \psi\left(u_{w, b}^{n}\right) f(w, b) d w d b .
$$

In addition, equation (27) is added to the set of constraints and $u_{w, b}^{n}$ is treated as an additional state variable for all $w$ and $b$ under non-welfarism. As pointed out in earlier research, e.g., Lehmann et al. (2020), it is typically not possible to fully identify the optimal policy rules in multi-screening problems algebraically. Yet, in our case, we can solve the two-dimensional differential equation for the multipliers of the incentive compatibility constraint in the form such that, for each type, the Lagrange multiplier associated with the incentive compatibility constraint in the $w$ dimension is proportional to what we can interpret as a weight-factor in the $w$ dimension, $\Gamma_{w, b}^{w}$. Simultaneously, the Lagrange multiplier associated with the incentive compatibility constraint in the $b$ dimension is proportional to the residual of the weight factor in the $w$ dimension, $1-\Gamma_{w, b}^{w}$. While this solution is clearly not unique (but depends on the weight factors), it provides considerable structure to the optimal policy rules. ${ }^{24}$

\footnotetext{
${ }^{24}$ Knowledge about these weights can in principle be gained through symmetry properties of the tax function. In particular, since both the marginal income tax and the marginal subsidy on charitable giving are functions of both gross income and charitable giving, we have $T_{y g}^{(w, b)}=T_{g y}^{(w, b)}$ for each type (given interior solutions).
} 
This approach allows us to define $\mathrm{ABC}$ factors associated with screening in the $w$ dimension identical to the ones in Section III, with the only difference being that each variable is a function of both $w$ and $b$ (instead of just $w$ ). Let us denote these factors $A_{w, b}^{w}$, $B_{w, b}^{w}$, and $C_{w, b}^{w}$, respectively. We can correspondingly define for the screening problem in the unobserved wealth dimension: ${ }^{25}$

$$
\begin{aligned}
& A_{w, b}^{b}=\varepsilon_{c(w, b)}^{l, c}, \\
& B_{w, b}^{b}=\int_{w}^{\infty}\left(\frac{1+\alpha^{D}}{1-\bar{\alpha}}-\delta_{w, b}\right) \frac{u_{c(w, b)}}{u_{c}^{(s, b)}} \exp \left(-\int_{w}^{s} \frac{u_{l c}^{(m, b)} l_{m, b}}{m} d m\right) \frac{f(s, b)}{1-F(w, b)} d s, \\
& C_{w, b}^{b}=\frac{1-F(w, b)}{c f(w, b)},
\end{aligned}
$$

where $\varepsilon_{c}^{l, c}=\left(\partial M R S_{l, c} / \partial c\right)\left(c / M R S_{l, c}\right)$. Finally, we define two-dimensional analogues of $\alpha^{d}$ and $\beta^{d}$ in Section III, showing how the degrees of positionality vary both with respect to labor (as before) and consumption:

$$
\begin{aligned}
& \alpha^{D}=\int_{0}^{\infty} \int_{0}^{\infty}\left(\Gamma_{w, b}^{w} B_{w, b}^{w} C_{w, b}^{w} \varepsilon_{l(w, b)}^{\alpha}-\left(1-\Gamma_{w, b}^{w}\right) B_{w, b}^{b} C_{w, b}^{b} \varepsilon_{c(w, b)}^{\alpha}\right) \alpha_{w, b} f(w, b) d w d b, \\
& \beta^{D}=\int_{0}^{\infty} \int_{0}^{\infty}\left(\Gamma_{w, b}^{w} B_{w, b}^{w} C_{w, b}^{w} \varepsilon_{l(w, b)}^{\beta}-\left(1-\Gamma_{w, b}^{w}\right) B_{w, b}^{b} C_{w, b}^{b} \varepsilon_{c(w, b)}^{\beta}\right) \beta_{w, b} M R S_{g, c}^{(w, b)} f(w, b) d w d b,
\end{aligned}
$$

where we have introduced $\varepsilon_{c}^{\alpha}=(\partial \alpha / \partial c)(c / \alpha)$ and $\varepsilon_{c}^{\beta}=(\partial \beta / \partial c)(c / \beta)$. The main results are presented in Proposition 4.

Proposition 4. Under welfarism and dual screening, the following results hold:

$$
\frac{T_{y}^{(w, b)}}{1-T_{y}^{(w, b)}}=\Gamma_{w, b}^{w} A_{w, b}^{w} B_{w, b}^{w} C_{w, b}^{w}-\left(1-\Gamma_{w, b}^{w}\right) A_{w, b}^{b} B_{w, b}^{b} C_{w, b}^{b}+\frac{\bar{\alpha}+\alpha^{D}}{1-\bar{\alpha}}
$$

(ii) If $G^{G o v}>0$, then

$$
\int_{0}^{\infty} \int_{0}^{\infty} M R S_{G, c}^{(w, b)}\left(\frac{1+\alpha^{D}}{1-\bar{\alpha}}+\Gamma_{w, b}^{w} B_{w, b}^{w} C_{w-b}^{w} \varepsilon_{l(w, b)}^{G, c}-\left(1-\Gamma_{w, b}^{w}\right) B_{w, b}^{b} C_{w, b}^{b} \varepsilon_{c(w, b)}^{G, c}\right) f(w, b) d w d b=1 .
$$

(iii) If $G^{\text {Gov }}>0$, then

\footnotetext{
${ }^{25}$ Jacobs and Boadway (2014) use a similar formulation as a function of the ratio of marginal utilities of consumption in a (single-screening) problem of optimal linear consumption taxation under nonlinear income taxation. The expression for $B_{w, b}^{b}$ can alternatively be written as$$
B_{w, b}^{b}=\int_{b}^{\infty}\left(\frac{1+\alpha^{D}}{1-\bar{\alpha}}-\delta_{w, b}\right) \exp \left(-2 \int_{b}^{t} \frac{u_{c c}^{(w, m)}}{u_{c}^{(w, m)}} d m\right) \exp \left(-\int_{b}^{t} \frac{\partial M R S_{l, c}^{(w, m)}}{\partial c} d l_{w, m}\right) \exp \left(-\int_{b}^{t} \frac{\partial M R S_{g, c}^{(w, m)}}{\partial c} d g_{w, m}\right) \frac{f(w, t)}{1-F(w, b} d t .
$$ 


$$
T_{g}^{(w, b)}=-1+\frac{1-\bar{\alpha}}{1+\alpha^{D}}\left(\Gamma_{w, b}^{w} B_{w, b}^{w} C_{w-b}^{w} \varepsilon_{l(w, b)}^{g, c}-\left(1-\Gamma_{w, b}^{w}\right) B_{w, b}^{w} C_{w-b}^{w} \varepsilon_{c(w, b)}^{g, c}\right)+\frac{1-\bar{\alpha}}{1-\bar{\beta}} \frac{\mu+\beta^{D}-\beta^{n o n}}{1+\alpha^{D}} .
$$

(iv) If $G^{\text {Gov }}=0$, then

$$
\begin{aligned}
T_{g}^{(w, b)} & =-1+\frac{1-\bar{\alpha}}{1+\alpha^{D}}\left(\Gamma_{w, b}^{w} B_{w, b}^{w} C_{w-b}^{w} \varepsilon_{l(w, b)}^{g, c}-\left(1-\Gamma_{w, b}^{w}\right) B_{w, b}^{w} C_{w-b}^{w} \varepsilon_{c(w, b)}^{g, c}\right) \\
& +\frac{1-\bar{\alpha}}{1-\bar{\beta}} \frac{\mu+(1-\mu) S^{0}+\beta^{D}-\beta^{n o n}}{1+\alpha^{D}}
\end{aligned}
$$

Under non-welfarism, (i) and (ii) continue to hold, whereas (iii) and (iv) are replaced with

$$
T_{g}^{(w, b)}=-1+\frac{1-\bar{\alpha}}{1+\alpha^{D}}\left(\Gamma_{w, b}^{w} B_{w, b}^{w} C_{w-b}^{w} \varepsilon_{l(w, b)}^{g, c}-\left(1-\Gamma_{w, b}^{w}\right) B_{w, b}^{b} C_{w, b}^{b} \varepsilon_{c(w, b)}^{g, c}+\delta_{w, b} M R S_{g, c}^{(w, b)}\right)
$$

$$
\begin{aligned}
& +\frac{1-\bar{\alpha}}{1-\bar{\beta}} \frac{\mu+\beta^{D}-\beta^{n o n}}{1+\alpha^{D}} \\
T_{g}^{(w, b)}= & -1+\frac{1-\bar{\alpha}}{1+\alpha^{D}}\left(\Gamma_{w, b}^{w} B_{w, b}^{w} C_{w-b}^{w} \varepsilon_{l(w, b)}^{g, c}-\left(1-\Gamma_{w, b}^{w}\right) B_{w, b}^{b} C_{w, b}^{b} \varepsilon_{c(w, b)}^{g, c}+\delta_{w, b} M R S_{g, c}^{(w, b)}\right) \\
& +\frac{1-\bar{\alpha}}{1-\bar{\beta}} \frac{\mu+(1-\mu) S^{0}+\beta^{D}-\beta^{n o n}}{1+\alpha^{D}}
\end{aligned}
$$

Starting with the marginal income tax rates, we note that the $\Gamma_{w, b}^{w} A_{w, b}^{w} B_{w, b}^{w} C_{w, b}^{w}$ component carries over from the single screening case with the same interpretation, although we have a weight factor here, and the marginal income tax will vary with both income and charitable giving. The second component, $-\left(1-\Gamma_{w, b}^{w}\right) A_{w, b}^{b} B_{w, b}^{b} C_{w, b}^{b}$, is novel and contributes to decrease the marginal income tax, ceteris paribus, since $\varepsilon_{c}^{l, c}>0$ due to the assumption that leisure is a normal good. Here too, the $A$ term reflects labor-related efficiency concerns, whereas the $B$ term reflects the desire for redistribution and the $C$ term the fatness of the upper tail of the wealth distribution. The intuition is that a lower marginal income tax rate leads to higher consumption, which makes mimicking in the $b$ dimension less attractive.

The other policy rules are extended in a similar way due to screening in the $b$ dimension. In particular, note that the properties of the utility function imply $\varepsilon_{c}^{G, c}>0$ and $\varepsilon_{c}^{g, c}>0$. Taken together, this means that terms proportional to $B_{w, b}^{b} C_{w, b}^{b}$ that are not due to concerns regarding relative consumption and relative charitable giving consistently work to i) decrease the marginal income taxes, ii) decrease the governmental provision of the public good, and iii) increase the marginal subsidy (or decrease the marginal tax) attached to charitable giving, ceteris paribus. The intuition is that higher income (due to lower marginal income taxation) increases the individuals' marginal willingness to pay for voluntary 
contributions. To relax the incentive compatibility constraints, the governmental contributions to the public good are, therefore, partly replaced with charitable giving.

The final term in each policy rule reflects the positional externalities. It is striking that the structure of these effects is very similar to that under the one-dimensional heterogeneity. Yet, note that $\alpha^{D}$ also reflects a relationship between the degree of consumption positionality and private consumption, measured with the labor supply held constant. If $\varepsilon_{c}^{\alpha}>0$, individuals with a higher level of consumption will suffer more from the positional consumption externality than those with a lower level of consumption, ceteris paribus. In the policy rules described above, this works to reduce $\alpha^{D}$. To keep individuals with a higher level of wealth from mimicking those with a lower wealth level, the government decreases the marginal income tax rate (which leads to an increase in $\bar{c}$ ), decreases the provision of the public good, and decreases the marginal subsidy on charitable giving, and vice versa if $\varepsilon_{c}^{\alpha}<0$. Similarly, if $\varepsilon_{c}^{\beta}>0$, individuals with a high consumption level will suffer more from the positional gifts externality than individuals with a lower level of consumption, ceteris paribus. This effect works to decrease $\beta^{D}$ in the policy rules in Proposition 4. The government can then relax the incentive compatibility constraint through a decrease in the marginal tax (or increase in the marginal subsidy) attached to charitable giving, which contributes to increase $\bar{g}$. The opposite policy incentive emerges if $\varepsilon_{c}^{\beta}<0$.

Finally, although $\varepsilon_{l}^{\alpha}=\varepsilon_{l}^{\beta}=\varepsilon_{l}^{G, c}=\varepsilon_{l}^{g, c}=0$ under leisure separability, $\varepsilon_{c}^{\alpha}$ and $\varepsilon_{c}^{\beta}$ are typically different from zero, meaning that $\alpha^{D}$ and $\beta^{D}$ do not vanish from the policy rules under such separability. Moreover, since $\varepsilon_{c}^{G, c}>0$ and $\varepsilon_{c}^{g, c}>0$, the corresponding terms in the policy rules will not vanish either. This implies that public good provision and the marginal tax treatment of charitable giving are not based on first-best policy rules under welfarism and leisure separability, as they were in the simpler model in Section III. This is interpretable as an implication of a broader result pointed out in earlier work, namely that the AtkinsonStiglitz theorem does not apply in general under multiple heterogeneity (e.g., Cremer et al., 2001; Saez, 2002).

\section{Numerical Illustration}

In this section, we supplement the theoretical analyses with numerical simulations. In doing so, we are able to go beyond the policy rules and illustrate how the levels of marginal and average taxation, as well as the overall redistribution policy, vary with key parameters and 
across policy objectives. We base our simulation on simple functional forms where the parameters are chosen in order to approximately mimic the U.S. economy with respect to mean gross income and the corresponding Gini coefficient. Moreover, we choose a functional, and corresponding parameter values, of the ability distribution for the thickness of the upper tail of the resulting income distribution to be fairly realistic; this is in particular important for the shape of the marginal income tax rates at high income levels. Within this framework, our main purpose is to examine how the optimal tax and expenditure policy varies with key parameters and to illustrate theoretical results.

We assume that the utility function takes the following logarithmic form for all types:

$$
\begin{aligned}
u_{w} & =\ln \left((1-\alpha) c_{w}+\alpha\left(c_{w}-\bar{c}\right)\right)+\xi \ln \left(1-l_{w}\right)+\sigma \ln \left(\chi+(1-\beta) g_{w}+\beta\left(g_{w}-\bar{g}\right)\right)+\rho \ln (G) \\
& =\ln \left(c_{w}-\alpha \bar{c}\right)+\xi \ln \left(1-l_{w}\right)+\sigma \ln \left(\chi+g_{w}-\beta \bar{g}\right)+\rho \ln (G)
\end{aligned}
$$

where $\alpha$ and $\beta$ denote constant degrees of consumption positionality and charitable positionality, respectively, which are the same for everybody. The logarithmic functional form is mathematically convenient, and variants of this utility function have been used in other numerical work on optimal taxation (e.g., Saez, 2001; Kanbur and Tuomala, 2013; Aronsson and Johansson-Stenman, 2018). In the numerical reference scenario, we set $\xi=1$, $\sigma=0.065, \rho=0.2, \chi=0.02, \mu=0.4, \alpha=0.2$, and $\beta=0.25$. We also present sensitivity analyses with respect to the key parameters $\mu, \alpha$, and $\beta$, while the other parameters are held constant. The social welfare function is assumed to be utilitarian, i.e., $\psi^{\prime}(\cdot)=1$ for all $w$.

Before-tax wage rates $(w)$ are distributed according to the Champernowne distribution with density function $f(w)=\varsigma\left(z^{\varsigma} w^{\varsigma-1}\right) /\left(z^{\varsigma}+w^{\varsigma}\right)^{2}$, where $\varsigma$ is the shape parameter and $z$ the scale parameter. ${ }^{26}$ Our parameter choices are based on Tuomala (2016): $\varsigma=3.3$ and $z=\exp (-1)$, implying a productivity Gini coefficient of about 0.3 .

We begin by illustrating the optimal tax policy and contributions to the public good in an economy where the consumers are not concerned with their relative consumption and relative charitable giving in Figure 1. This scenario corresponds to the model examined in Section II and means that $\alpha=\beta=0$ in equation (30). The following Figures $2-4$ present the optimal tax policy and contributions to the public good in economies where the individuals are concerned with their relative consumption and relative charitable giving such that $\alpha>0$ and $\beta>0$. These simulations correspond to the models examined in Section III.

\footnotetext{
${ }^{26}$ Tuomala (2016) argues that the Champernowne distribution gives results more in accordance with empirical evidence in the upper tail of the distribution, compared with the lognormal distribution.
} 
Figure 1. Optimal taxation and charitable giving under varying transaction costs.

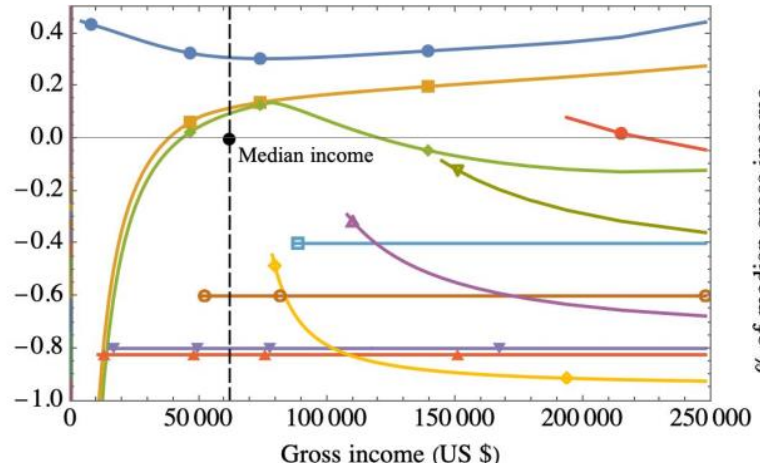

- $T_{y}[\mathrm{~W}, \mu=0.4]=\mathrm{T} / \mathrm{y}[\mathrm{W}, \mu=0.4] * T_{y}[\mathrm{NW}, \mu=0]$

$\Delta T_{g}[\mathrm{~W}, \mu=0] \vee T_{g}[\mathrm{~W}, \mu=0.2] \circ T_{g}[\mathrm{~W}, \mu=0.4]$

ㅁ $T_{g}[\mathrm{~W}, \mu=0.6] \diamond T_{g}[\mathrm{NW}, \mu=0] \Delta T_{g}[\mathrm{NW}, \mu=0.2]$

$\nabla T_{g}[\mathrm{NW}, \mu=0.4] \bullet T_{g}[\mathrm{NW}, \mu=0.6]$

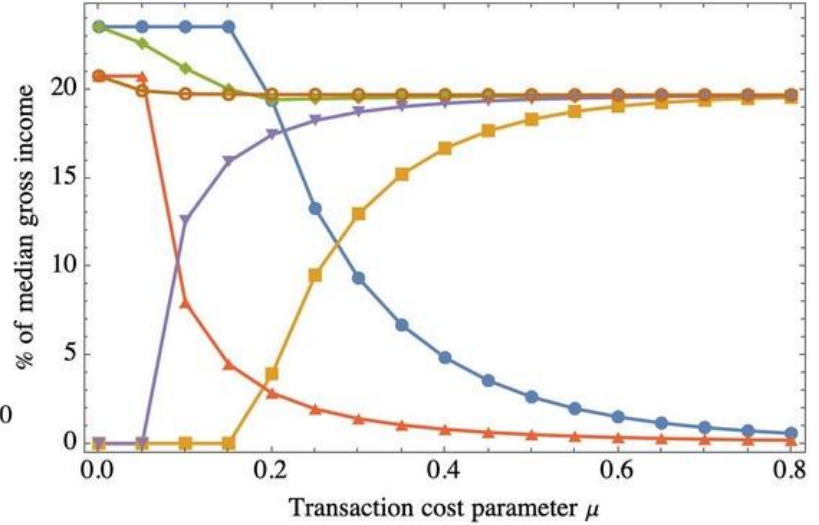

$\rightarrow$ Average private contributions (W) $-\square$ - Public ctb per capita (W)

$\rightarrow$ Aggregate ctb per capita $(\mathrm{W}) \multimap$ Average private ctb (NW)

$\rightarrow$ Public ctb per capita (NW) $\rightarrow$ Aggregate ctb per capita (NW)

Note: The left part plots marginal and average income tax rates and the marginal subsidy on charitable giving for different transaction costs, while the right part shows how private and public contributions to the public good vary with this cost. $\mathrm{W}$ denotes welfarism and $\mathrm{NW}$ non-welfarism; ctb = contribution.

Figure 1 examines the effects of varying the transaction cost $\mu$, in a model without any relative concerns $(\alpha=\beta=0)$. The left part shows that the marginal income tax $\left(T_{y}\right)$ schedule follows the well-known U-shaped pattern (e.g., Saez, 2001; Tuomala, 2016), which is due to our relatively fat-tailed ability distribution (e.g. compared to log-normal ones), and the average tax rate $(T / y)$ increases in income. The optimal marginal income tax schedules in the figure reflect a welfarist objective; however, the pattern is very similar under nonwelfarism (as we saw in Section II, the two governments implement the same policy rule for marginal income taxation).

Our simulations clearly support the idea that the government ought to subsidize charitable giving at the margin. In accordance with the theoretical results, these subsidies differ considerably between the welfarist and non-welfarist governments. The welfarist government implements a flat subsidy rate, since the utility function (30) is characterized by leisure separability, whereas the marginal subsidy rate implemented by the non-welfarist government increases with the before-tax income. Note that these curves are shown only for the interval where people contribute a positive amount; thus, to the left of each such curve we have bunching at zero contributions (which implies that the optimal marginal subsidy rate is not unique in the corresponding interval). Consistent with Propositions 1a and $2 \mathrm{a}$, the marginal subsidy on charitable giving decreases sharply with the transaction cost under both policy objectives and may even turn into a marginal tax in the non-welfarist case. 
The right part of Figure 1 shows, as expected, that the average charitable giving decreases and the public contributions increase with the transaction cost attached to private contributions. When the transaction cost is zero, the entire public good supply comes from voluntary contributions under both the welfarist and the non-welfarist policy objective, consistent with Propositions 1a and $2 \mathrm{a} .{ }^{27}$ As indicated above, the intuition is that public provision and voluntary contributions are equally resource efficient in that case, whereas the voluntary contributions come with the additional benefit of warm glow, which the welfarist government recognizes as a welfare gain, and in terms of a redistributive gain recognized by the non-welfarist government. Consistent with the latter, note from the left part of the figure that the average tax rate, and thus the total amount of taxes paid, actually becomes negative for high-income earners when the transaction cost is zero! The explanation is that these individuals must receive large enough subsidies in order to contribute sufficiently. In turn, these subsidies are key ingredients of the redistribution policy.

Let us now add concerns about relative consumption and relative charitable giving. The left part of Figure 2 shows that the marginal income tax rates implemented by a welfarist government are higher throughout the income distribution than in Figure $1 .^{28}$ The same qualitative result (albeit not reported) applies under non-welfarism. This is a direct consequence of the relative consumption concerns, leading to negative positional consumption externalities. ${ }^{29}$ Correspondingly, the tax system is also more redistributive in the sense that the average income tax is lower among low-income earners and higher among high-income earners than in Figure 1. The intuition is that positional consumption externalities allow the government to raise some of its revenue from non-distortive taxation, which in turn opens up for more redistribution. To further emphasize the results presented in Figures 1 and 2, we show in Table A1 in the Appendix that the optimal distribution of disposable income is more equal under relative concerns than in their absence, ceteris paribus, and that the optimal distribution of disposable incomes is quite similar under the welfarist and non-welfarist governments.

\footnotetext{
${ }^{27}$ As we saw in Section III, this result continues to apply if we add the assumption that people are concerned with their relative consumption and relative charitable giving. To save space, we therefore refrain from showing the corresponding diagrams for the more general model where $\alpha>0$ and $\beta>0$.

${ }^{28}$ This is in line with findings in other studies on optimal taxation and relative consumption (e.g., Kanbur and Tuomala, 2013; Aronsson and Johansson-Stenman, 2018).

${ }^{29}$ Since the utility function in equation (30) is additively separable, one can show that both the marginal and average income tax rates are independent of $\beta$.
} 
Figure 2. Tax policy, charitable giving, and variation in $\beta$.
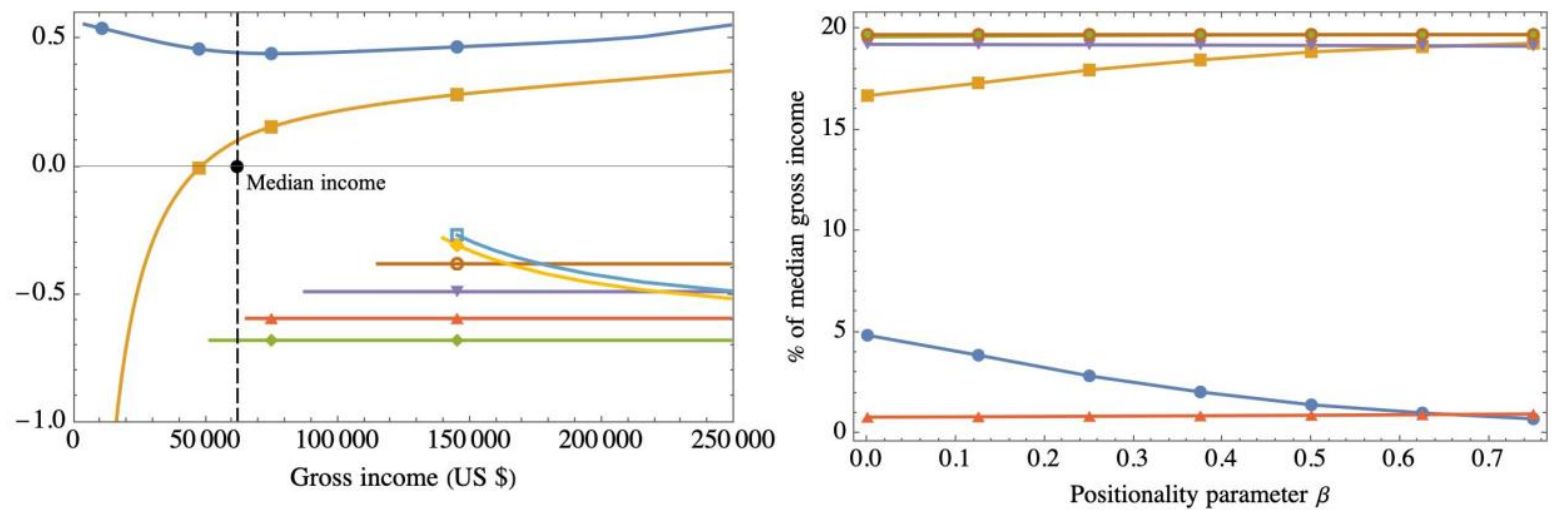

- $T_{y}[\mathrm{~W}, \beta=0.25]=\mathrm{T} / \mathrm{y}[\mathrm{W}, \beta=0.25] * T_{g}[\mathrm{~W}, \beta=0]$

$\rightarrow$ Average private contributions (W) $-\cdots$ Public ctb per capita (W)

$\Delta T_{g}[\mathrm{~W}, \beta=0.25] \vee T_{g}[\mathrm{~W}, \beta=0.5] \quad T_{g}[\mathrm{~W}, \beta=0.75]$

ㅁ $T_{g}[\mathrm{NW}, \beta=0] \circ T_{g}[\mathrm{NW}, \beta=0.75]$

$\rightarrow$ Aggregate ctb per capita $(\mathrm{W}) \multimap$ Average private ctb (NW)

$\rightarrow$ Public ctb per capita (NW) $\rightarrow$ Aggregate ctb per capita (NW)

Note: The left part plots marginal and average income tax rate and the marginal subsidy on charitable giving, while the right part shows how the private and public contributions to the public good vary with the degree of charitable positionality, $\beta$. W denotes welfarism and NW non-welfarism; $\mathrm{ctb}=$ contribution.

As expected from Proposition 3a, the left part of Figure 2 also shows that the marginal tax treatment of charitable giving differs substantially between the two policy objectives. The marginal subsidy is again constant among givers under welfarism and increases with the before-tax income under non-welfarism, although the levels of the marginal subsidies differ from those in Figure 1. The marginal subsidy on charitable giving decreases with the degree of gifts positionality, $\beta$, under welfarism. In the non-welfarist case, the marginal subsidy is much less sensitive to (and even increases with) $\beta$. This is because very few individuals contribute to charity under non-welfarism in our model. As explained in Section III, this means that $\beta^{\text {non }}$ becomes large, which reduces the social cost of the positional gifts externality. The right part of Figure 2 shows, correspondingly, that the average charitable giving decreases with $\beta$, and that the governmental contribution increases with $\beta$, under welfarism. These relationships are absent under a non-welfarist objective.

Figure 3 shows how the marginal tax treatment of charitable giving as well as the private and public contributions to the public good vary with the degree of consumption positionality, $\alpha$, when all other parameters reflect the numerical reference scenario. The left part illustrates how the optimal marginal subsidy schedule for charitable giving varies with $\alpha \cdot{ }^{30}$ In accordance with the policy rules for $T_{g}$ presented in Proposition $3 \mathrm{a}$, we can see that a

\footnotetext{
${ }^{30}$ Again for simplicity, we only present one curve each for the marginal and average income tax rates (corresponding to the numerical reference scenario where $\alpha=0.2$ and $\beta=0.25$ ), although these rates will now vary considerably with $\alpha$, as shown by comparing Figures 1 and 2 .
} 
higher $\alpha$ is always associated with higher marginal subsidies to charitable giving, regardless of whether the government is welfarist or non-welfarist. The intuition is straightforward: The welfarist government aims at internalizing the positional consumption externality by incentivizing a shift in expenses from consumption to charitable giving. A non-welfarist government additionally raises the marginal subsidies to high-income earners. Since redistribution is costly, it is socially preferable that high-income earners contribute more than low-income earners to charity.

Figure 3. Optimal tax schedules and charitable giving for different values of $\alpha$
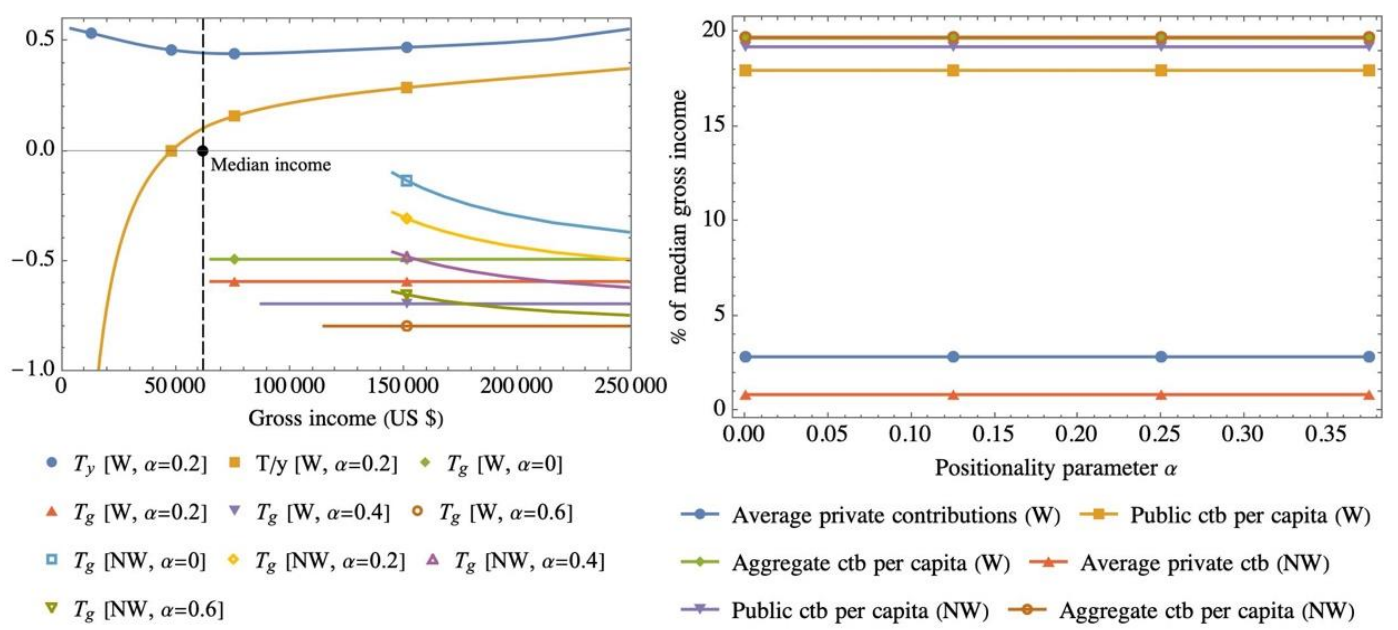

Note: In the left part of the figure, $T_{y}$ and $T / y$ are plotted for the reference scenario, while $T_{g}$ varies with the degree of consumption positionality. In the right part of the figure, $\mathrm{ctb}=$ contribution.

According to the right part of Figure 3, $\alpha$ does not affect the levels of charitable giving; instead, the tax system is adjusted in such a way that charitable giving remains constant. Intuitively, an increase in $\alpha$ implies, in addition to higher marginal subsidies on charitable giving, increased marginal income taxes. The latter leads to lower disposable incomes and contributes to reduce the levels of charitable giving, which tends to offset the positive effect of increased subsidization. With the functional form assumptions presented above, the two effects cancel out. Still, charitable giving and governmental contributions to the public good differ between the welfarist and non-welfarist objectives, such that individual contributions are higher under welfarism than non-welfarism and vice versa for public provision.

While the results presented in Figures 2 and 3 are thus based on mean-value comparisons, i.e., individuals compare their own consumption and charitable giving with economy-wide averages, Figure 4 supplements these simulations by showing numerical results based on within-type comparisons (as in Section III C). 
Figure 4. Optimal taxation under within-type comparisons

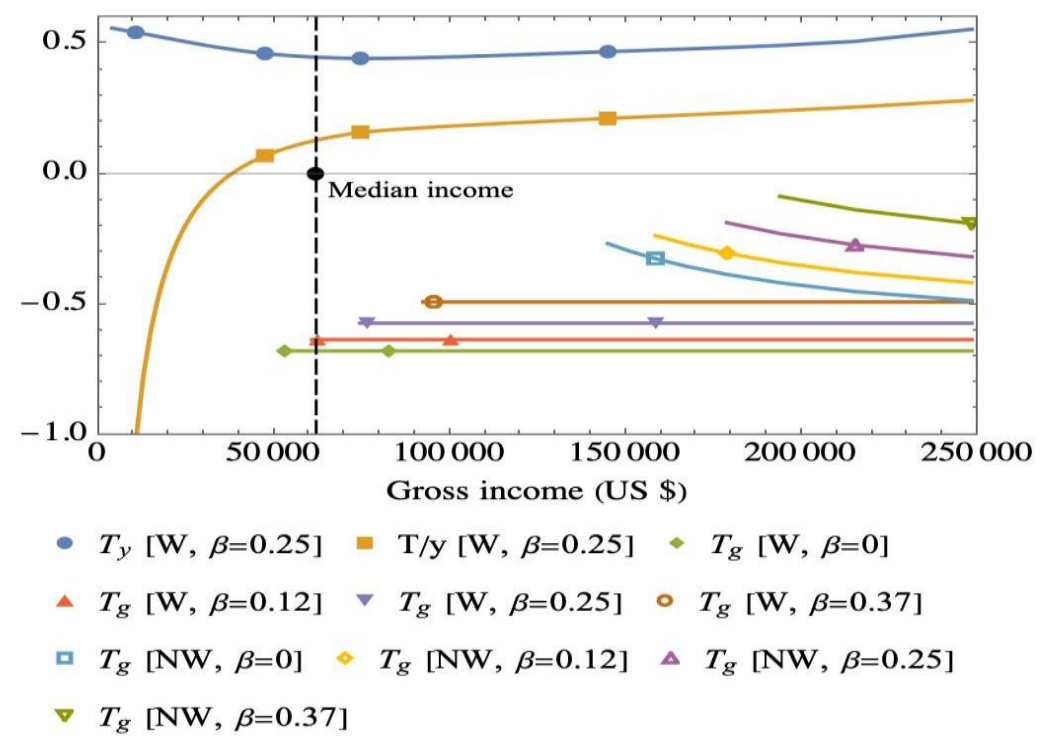

Note: The marginal and average income tax rates are based on the numerical reference scenario where $\alpha=0.2$ and $\beta=0.25$. The marginal subsidies to charitable giving are calculated for different values of $\beta$.

Figure 4 is similar to the left part of Figure 2, which shows the corresponding results under mean-value comparisons. Since our functional form assumption for the utility function (30) means that the degrees of positionality are the same for everybody, the marginal subsidy to charitable giving is constant (independent of income) here too under welfarism, while it increases in income under non-welfarism. The structure of marginal and average income taxation is also similar to that under mean-value comparisons.

It is worth emphasizing two important differences between mean-value comparisons and within-type comparisons for the marginal tax treatment of charitable giving. First, the marginal subsidies to charitable giving decrease with $\beta$ under within-type comparisons regardless of whether the government is welfarist or non-welfarist. Under mean-value comparisons, the negative relationship between the marginal subsidy to charitable giving and $\beta$ only applies under welfarism. The intuition is that zero-bunching in terms of charitable giving does not affect the marginal tax treatment of charitable giving under within-type comparisons, as explained in Section 3. In other words, and contrary to the case of meanvalue comparisons, the variable $\beta^{\text {non }}$ does not affect the underlying policy rules here. Therefore, the welfarist and non-welfarist governments always change the marginal subsidies/taxes on charitable giving in the same qualitative way in response to a change in $\beta$.

Second, the marginal subsidies to charitable giving are much lower under within-type comparisons than under mean-value comparisons. Intuitively, as only high-income individuals give to charity, the reference levels, and ceteris paribus the marginal utilities of 
giving, are higher under within-type than mean-value comparisons. Consequently, to reach a given level of the public good, we need less subsidization under within-type comparisons.

\section{Conclusion}

Let us return to the question posed initially: What is the optimal tax treatment of charitable giving? While the answer is, naturally, complex, we would like to emphasize eight key results. 1) For a welfarist government, zero transaction costs and leisure separability, regardless of relative concerns, together imply that charitable giving should be subsidized to an extent that completely crowds out governmental contribution to the public good. 2) The same result holds for a non-welfarist government that does not value the warm glow of giving. 3) The optimal marginal subsidy to charitable giving decreases strongly with the size of the transaction costs. 4) When these costs are sufficiently high, the marginal subsidy decreases with the degree of charitable positionality, and the marginal subsidy is much lower for a nonwelfarist than for a welfarist government. 5) A welfarist government would implement a flat rate marginal subsidy on charitable giving under leisure separability, regardless of whether individuals are concerned with their relative consumption and relative charitable giving. Conditions are presented for when the marginal subsidy increases or decreases with income for a non-welfarist government. 6) Zero bunching in terms of charitable giving implies higher marginal subsidies for the contributors, ceteris paribus. 7) In the general case where the utility functions are non-separable, we also show how public good provision and the marginal subsidies/taxes on charitable giving supplement the income tax for purposes of redistribution, and how the redistributive roles of these two instruments depend on the income tax wedge. 8) Stronger concerns for relative charitable giving tend to support lower marginal subsidies, whereas concerns for relative consumption work in the other direction. These, and several other, qualitative insights continue to hold in our dual screening setting.

\section{Appendix}

\section{Proof of Propositions 3 (Propositions 1 and 2 follow as special cases)}

We start by proving Proposition $3 \mathrm{~b}$ for the welfarist case. In the optimal control problems, we treat utility, $u_{w}$, as a state variable, while $l_{w}, g_{w}, G^{G o v}, \bar{c}$, and $\bar{g}$ are control variables. Consumption, $c_{w}$, is defined by the inverse of the function $u(\cdot)$ in (17), i.e., $c_{w}=h\left(l_{w}, g_{w}, G, \bar{c}, \bar{g}, u_{w} ; w\right)$. The Lagrangean becomes 


$$
\begin{aligned}
L & =\int_{0}^{\infty} \psi\left(u_{w}\right) f(w) d w+\lambda\left(\int_{0}^{\infty}\left(w l_{w}-h\left(l_{w}, g_{w}, G, \bar{g}, \bar{c}, u_{w} ; w\right)-g_{w}\right) f(w) d w-G^{G o v}\right) \\
& +\int_{0}^{\infty}\left(\theta_{w} \frac{\left.u_{l}\left(h\left(l_{w}, g_{w}, G, \bar{g}, \bar{c}, u_{w} ; w\right), l_{w}, g_{w}, G\right)\right) l_{w}}{w}-\dot{\theta}_{w} u_{w}\right) d w \\
& +\eta\left(\bar{c}-\int_{0}^{\infty} h\left(l_{w}, g_{w}, G, \bar{g}, \bar{c}, u_{w} ; w\right) f(w) d w\right)+\zeta\left(\bar{g}-\int_{0}^{\infty} g_{w} f(w) d w\right)+\int_{0}^{\infty} \phi_{w} g_{w} d w+\Upsilon G^{G o v}
\end{aligned}
$$

To avoid clutter, we suppress the type indicator $w$ except in integral expressions. By using $h_{l}=-u_{l} / u_{c}=-M R S_{l, c}$ and $h_{G}=-u_{G} / u_{c}=-M R S_{G, c}$, the social first-order conditions for $l$ and $G^{G o v}$, respectively, if $G^{G o v}>0$, can be written as

$$
\begin{aligned}
& w+M R S_{l, c}=-\frac{\theta u_{c} M R S_{l, c}}{\lambda f(w) w}\left(1+\varepsilon_{l}^{l c}\right)-\frac{\eta}{\lambda} M R S_{l, c}=0 \\
& \int_{0}^{\infty} M R S_{G, c}^{(w)}\left(1+\frac{\eta}{\lambda}\right) f(w) d w+\frac{1}{\lambda} \int_{0}^{\infty} \theta_{w} u_{c}^{(w)} \varepsilon_{l}^{G c} \frac{M R S_{G, c}^{(w)}}{w} d w=1 .
\end{aligned}
$$

We can derive an expression for $\eta / \lambda$ from the social first-order condition for $\bar{c}$. By using $h_{\bar{c}}=-u_{\bar{c}} / u_{c}=-M R S_{\bar{c}, c}$, the social first-order condition for $\bar{c}$ can be written as follows:

$$
\frac{1}{\lambda} \int_{0}^{\infty} \theta_{w} u_{c}^{(w)} \frac{\partial M R S_{\bar{c}, c}^{(w)}}{\partial l} \frac{l_{w}}{w} d w+\int_{0}^{\infty} M R S_{\bar{c}, c}^{(w)} f(w) d w+\frac{\eta}{\lambda}\left(1+\int_{0}^{\infty} M R S_{\bar{c}, c}^{(w)} f(w) d w\right)=0 .
$$

Since $\alpha=-M R S_{\bar{c}, c}, \bar{\alpha}=\int_{0}^{\infty} \alpha_{w} f(w) d w$, and $\partial M R S_{\bar{c}, c} / \partial l=-\partial \alpha / \partial l,(\mathrm{~A} 4)$ implies

$$
\frac{\eta}{\lambda}=\frac{\bar{\alpha}}{1-\bar{\alpha}}+\frac{1}{1-\bar{\alpha}} \frac{1}{\lambda} \int_{0}^{\infty} \frac{\partial \alpha^{(w)}}{\partial l} \frac{l_{w}}{w} d w=\frac{\bar{\alpha}+\alpha^{d}}{1-\bar{\alpha}}
$$

Substitute (A5) into (A2) and (A3) and use the private first-order condition $w+M R S_{l, c}=w T_{y}$. Finally, use $B_{w} C_{w}=\left(u_{c}^{(w)} \theta_{w}\right) /(\lambda w f(w))$ and rearrange to obtain (i) and the first part of (ii) in Proposition $3 b$.

By using $h_{g}=-u_{g} / u_{c}=-M R S_{g, c}$ and $h_{\bar{g}}=-u_{\bar{g}} / u_{c}=-M R S_{\bar{g}, c}=\beta M R S_{g, c}$, the social first-order conditions for $g$ and $\bar{g}$, respectively, can be written as follows if $G^{G o v}>0$ :

$$
\begin{gathered}
\operatorname{MRS}_{g, c}\left(1+\frac{\eta}{\lambda}\right)=-\frac{\theta u_{c}}{\lambda f(w)} \frac{\partial M R S_{g, c}}{\partial l} \frac{l}{w}+\mu+\frac{\zeta}{\lambda}-\frac{\phi}{\lambda f(w)} \\
\frac{\zeta}{\lambda}=\frac{1}{\lambda} \int_{0}^{\infty} \theta_{w} u_{c}^{(w)}\left(\frac{\partial \beta_{w}}{\partial l} M R S_{g, c}^{w}+\beta_{w} \frac{\partial M R S_{g, c}^{w}}{\partial l}\right) \frac{l_{w}}{w} d w+\left(1+\frac{\eta}{\lambda}\right) \int_{0}^{\infty} \beta_{w} M R S_{g, c}^{(w)} f(w) d w .(\mathrm{A} 7)
\end{gathered}
$$

Substituting (A6) into (A7) gives 


$$
\frac{\zeta}{\lambda}=\frac{\mu \bar{\beta}}{1-\bar{\beta}}+\frac{1}{1-\bar{\beta}} \frac{1}{\lambda} \int_{0}^{\infty} \theta_{w} u_{g}^{(w)} \frac{\partial \beta_{w}}{\partial l} \frac{l_{w}}{w} d w-\frac{1}{1-\bar{\beta}} \frac{1}{\lambda} \int_{0}^{\infty} \beta_{w} \phi_{w} d w=\frac{\mu \bar{\beta}+\beta^{d}-\beta^{n o n}}{1-\bar{\beta}} .
$$

Substitute (A8) into (A6) and use the private first-order condition $M R S_{g, c}=1+T_{g}$. Finally, write the first term on the right-hand side of (A6) in elasticity form and use $B_{w} C_{w}=\left(u_{c}^{(w)} \theta_{w}\right) /(\lambda w f(w))$. This gives the policy rule for $T_{g}$ in Proposition $3 \mathrm{~b}$. If $G^{G o v}=0$, the derivation procedure is the same, except that (A3) does not hold and $(1-\mu) S^{0}$ will be added to the right-hand side of (A6), where $S^{0}$ is given by

$$
S^{0}=\frac{\Upsilon}{\lambda}=1-\left(\int_{0}^{\infty} \frac{M R S_{G, c}^{(w)}}{1-\bar{\alpha}} f(w) d w\right)_{G^{G o v}=0} .
$$

Proposition 3a follows as the special case where the utility functions are leisure separable, which implies $\varepsilon_{l(w)}^{G c}=\varepsilon_{l(w)}^{g c}=\alpha^{d}=\beta^{d}=0$ for all $w$. The corresponding policy rules in Proposition 1 follow as special cases where $\alpha_{w}=\beta_{w}=0$ for all $w$, in which $\eta=\zeta=0$.

In order to show (iv) of Proposition $3 b$ in the welfarist case, note that under zero transaction costs the social first-order conditions for $g_{w}$ and $G^{G o v}$ can be written as

$$
\begin{aligned}
& g_{w}: \quad M R S_{g, c}^{(w)}+\frac{1-\bar{\alpha}}{1+\alpha^{d}} \varepsilon_{l(w)}^{g c} B_{w} C_{w} M R S_{g, c}^{(w)}+\frac{1-\bar{\alpha}}{1-\bar{\beta}} \frac{\beta^{n o n}-\beta^{d}}{1+\alpha^{d}}-\frac{1-\bar{\alpha}}{1-\bar{\beta}} \frac{S^{0}}{1+\alpha^{d}} \leq 0 \forall w \\
& G^{G o v}: \int_{0}^{\infty} M R S_{G, c}^{(w)}\left(\frac{1+\alpha^{d}}{1-\bar{\alpha}}+\varepsilon_{l}^{G c} B_{w} C_{w}\right) f(w) d w+S^{0}-1=0,
\end{aligned}
$$

where strict equality holds for individuals who contribute to the public good $\left(g_{w}>0\right)$. Also, recall that $S^{0}=0$ if $G^{G o v}>0$ and $S^{0}>0$ if $G^{G o v}=0$. Assume now that we have an interior solution in the sense that both the government and some individuals contribute. This means that $S^{0}=0$. However, the social first-order conditions for $g_{w}$ are not satisfied in this case. Instead, if $\beta^{d} \leq \beta^{\text {non }}, \alpha^{d}>-1$, and $\varepsilon_{l(w)}^{g c} \geq 0$, we obtain

$$
M R S_{g, c}^{(w)}+\frac{1-\bar{\alpha}}{1+\alpha^{d}} \varepsilon_{l(w)}^{g c} B_{w} C_{w} M R S_{g, c}^{(w)}+\frac{1-\bar{\alpha}}{1-\bar{\beta}} \frac{\beta^{n o n}-\beta^{d}}{1+\alpha^{d}}>0
$$

since all three terms on the left-hand side are positive. Thus, the only way of satisfying the social first-order conditions simultaneously is to choose $G^{G o v}=0$, so $S^{0}>0$. It is also obvious that we do not need all three terms to be positive for this result to hold; it suffices that their sum is positive.

Result (iv) of Proposition 3a, i.e., under leisure separability, follows as the special case where $\varepsilon_{l(w)}^{G c}=\varepsilon_{l(w)}^{g c}=\alpha^{d}=\beta^{d}=0$ for all $w$. Again the corresponding results in Proposition 1 
follow as special cases where $\alpha_{w}=\beta_{w}=0$ for all $w$, in which $\eta=\zeta=0$.

We will next prove Proposition $3 b$ for the non-welfarist case, where the Lagrangean can be written as follows:

$$
\begin{aligned}
L & =\int_{0}^{\infty} \psi\left(u_{w}^{n}\right) f(w) d w+\lambda\left(\int_{0}^{\infty}\left(w l_{w}-h\left(l_{w}, g_{w}, G, \bar{g}, \bar{c}, u_{w} ; w\right)-g_{w}\right) f(w) d w-G^{G o v}\right) \\
& +\int_{0}^{\infty}\left(\theta_{w} \frac{\left.u_{l}\left(h\left(l_{w}, g_{w}, G, \bar{g}, \bar{c}, u_{w} ; w\right), l_{w}, g_{w}, G\right)\right) l_{w}}{w}-\dot{\theta}_{w} u_{w}\right) d w \\
& +\eta\left(\bar{c}-\int_{0}^{\infty} h\left(l_{w}, g_{w}, G, \bar{g}, \bar{c}, u_{w} ; w\right) f(w) d w\right)+\zeta\left(\bar{g}-\int_{0}^{\infty} g_{w} f(w) d w\right) \\
& +\int_{0}^{\infty} \phi_{w} g_{w} d w+\int_{0}^{\infty} \vartheta_{w}\left(v\left(h\left(l_{w}, g_{w}, G, \bar{g}, \bar{c}, u_{w} ; w\right), l_{w}, \bar{c}, G ; w\right)-u_{w}^{n}\right) d w+\Upsilon G^{G o v}
\end{aligned}
$$

There are two state variables here, $u$ and $u^{n}$, whereas the control variables are the same as above. Note that $v_{c} h_{l}+v_{l}=0, v_{c} h_{G}+v_{G}=0$, and $v_{c} h_{\bar{c}}+v_{\bar{c}}=0$, which means that the social first-order conditions for $l, G^{G o v}$, and $\bar{c}$ coincide with equations (A2), (A3), and (A4), respectively. If $G^{G o v}>0$, the social first-order conditions for $g$ and $\bar{g}$, i.e., analogues of equations (A6) and (A7), can now be written as

$$
\begin{aligned}
& \operatorname{MRS}_{g, c}\left(1+\frac{\eta}{\lambda}\right)=-\frac{\theta u_{c}}{\lambda f(w)} \frac{\partial M R S_{g, c}}{\partial l} \frac{l}{w}+\mu+\frac{\zeta}{\lambda}-\frac{\phi}{\lambda f(w)}+\frac{\psi^{\prime}(u) v_{c}}{\lambda} M R S_{g, c} \\
& \frac{\zeta}{\lambda}=\frac{1}{\lambda} \int_{0}^{\infty} \theta_{w} u_{c}^{(w)}\left(\frac{\partial \beta_{w}}{\partial l} M R S_{g, c}^{w}+\beta_{w} \frac{\partial M R S_{g, c}^{w}}{\partial l}\right) \frac{l_{w}}{w} d w+\left(1+\frac{\eta}{\lambda}\right) \int_{0}^{\infty} \beta_{w} M R S_{g, c}^{(w)} f(w) d w \\
& -\frac{1}{\lambda} \int_{0}^{\infty} \psi^{\prime}\left(u_{w}\right) f(w) v_{c}^{(w)} \beta_{w} M R S_{g, c}^{(w)} d w
\end{aligned}
$$

Combining them gives equation (A8) above. Finally, substituting (A8) into (A10) and using the private first-order condition for charitable giving, we can derive the non-welfarist policy rule for $T_{g}$ in Proposition 3b. Again, the derivation is analogous if $G^{G o v}=0$ at the social optimum. Proposition 3a follows as the special case where the utility functions are leisure separable. The corresponding policy rules in Proposition 2 follow as special cases where $\alpha_{w}=\beta_{w}=0$ for all $w$, in which $\eta=\zeta=0$.

To show (iv) in the non-welfarist case, note that zero transaction cost implies that the social first-order conditions for $g_{w}$ and $G^{G o v}$ can be written as $g_{w}: \operatorname{MRS}_{g, c}^{(w)}\left(1-\delta_{w} \frac{1-\bar{\alpha}}{1+\alpha^{d}}\right)+\varepsilon_{l(w)}^{g c} \frac{1-\bar{\alpha}}{1+\alpha^{d}} B_{w} C_{w} M R S_{g, c}^{(w)}+\frac{1-\bar{\alpha}}{1-\bar{\beta}} \frac{\beta^{n o n}-\beta^{d}}{1+\alpha^{d}}-\frac{1-\bar{\alpha}}{1-\bar{\beta}} \frac{S^{0}}{1+\alpha^{d}} \leq 0 \forall w$, 


$$
G^{G o v}: \int_{0}^{\infty} M R S_{G, c}^{(w)}\left(\frac{1+\alpha^{d}}{1-\bar{\alpha}}+\varepsilon_{l}^{G c} B_{w} C_{w}\right) f(w) d w+S^{0}-1=0
$$

Based on the same reasoning as in the welfarist case, if $\beta^{\text {non }} \geq \beta^{d}$ and $\alpha^{d}>-1$, we must have $G^{G o v}=0$ (such that $S^{0}>0$ ) for these conditions to hold simultaneously. The corresponding policy rules in Proposition 2a follow as special cases where $\alpha_{w}=\beta_{w}=0$ for all $w$, in which $\eta=\zeta=0$.

\section{Proof of Proposition 4}

To shorten the notation, let $\omega=(w, b) \in \Omega$ represent type in two-dimensional space, and let $f(\omega)=f(w, b)$ denote the corresponding density function such that

$$
\int_{\Omega} f(\omega) d \omega=\int_{0}^{\infty} \int_{0}^{\infty} f(w, b) d b d w=1 .
$$

In a way similar to the proof of Propositions 3 above, we treat utility, $u_{\omega}$, as a state variable, while $l_{\omega}, g_{\omega}, G^{G o v}, \bar{c}$, and $\bar{g}$ are control variables. Consumption, $c_{\omega}$, is defined by the inverse of the function $u(\cdot)$ in equation (27), i.e., $c_{\omega}=h\left(l_{\omega}, g_{\omega}, G, \bar{c}, \bar{g}, u_{\omega} ; \omega\right)$.

With a welfarist government, the Lagrangean can be written as follows:

$$
\begin{aligned}
L & =\int_{\Omega} \psi\left(u_{\omega}\right) f(\omega) d \omega \\
& +\lambda\left(\int_{\Omega}\left(w_{\omega} l_{\omega}-h\left(l_{\omega}, g_{\omega}, \bar{c}, \bar{g}, G, u_{\omega} ; \omega\right)-g_{\omega}\right) f(\omega) d \omega-G^{G o v}\right) \\
& +\int_{\Omega}\left(-\left(\dot{\theta}_{\omega}^{\omega}+\dot{\theta}_{\omega}^{b}\right) u_{\omega}+\theta_{\omega}^{w} \frac{l_{\omega} u_{l}^{(\omega)}}{w_{\omega}}-\theta_{\omega}^{b} u_{c}^{(\omega)}\right) d \omega \\
& +\eta\left(\bar{c}-\int_{\Omega} h\left(l_{\omega}, g_{\omega}, G, \bar{c}, \bar{g}, u_{\omega} ; \omega\right) f(\omega) d \omega\right) \\
& +\zeta\left(\bar{g}-\int_{\Omega} g_{\omega} f(\omega) d \omega\right)+\int_{\Omega} \phi_{\omega} g_{\omega} d \omega+\Upsilon G^{G o v}
\end{aligned}
$$

Under non-welfarism, equation (33) is added to the set of constraints, and $u_{\omega}^{n}$ will be used as an additional state variable. Therefore, the Lagrangean is given by

$$
\begin{aligned}
L & =\int_{\Omega} \psi\left(u_{\omega}^{n}\right) f(\omega) d \omega \\
& +\lambda\left(\int_{\Omega}\left(w_{\omega} l_{\omega}-h\left(l_{\omega}, g_{\omega}, \bar{c}, \bar{g}, G, u_{\omega} ; \omega\right)-g_{\omega}\right) f(\omega) d \omega-G^{G o v}\right) \\
& +\int_{\Omega}\left(-\left(\dot{\theta}_{\omega}^{w}+\dot{\theta}_{\omega}^{b}\right) u_{\omega}+\theta_{\omega}^{w} \frac{l_{\omega} u_{l}^{(\omega)}}{w_{\omega}}-\theta_{\omega}^{b} u_{c}^{(\omega)}\right) d \omega \\
& +\eta\left(\bar{c}-\int_{\Omega} h\left(l_{\omega}, g_{\omega}, G, \bar{c}, \bar{g}, u_{\omega} ; \omega\right) f(\omega) d \omega\right)+\zeta\left(\bar{g}-\int_{\Omega} g_{\omega} f(\omega) d \omega\right) \\
& +\int_{\Omega} \vartheta_{\omega}\left(v\left(h\left(l_{\omega}, g_{\omega}, G, \bar{c}, \bar{g}, u_{\omega} ; \omega\right), l_{\omega}, \bar{c}, G ; \omega\right)-u_{\omega}^{n}\right) d \omega+\int_{\Omega} \phi_{\omega} g_{\omega} d \omega+\Upsilon G^{G o v}
\end{aligned}
$$


Note that the "laundered utility function" $v(\cdot)$ in the final row of equation (A13) satisfies

$$
\begin{aligned}
& v_{c} h_{l}+v_{l}=u_{c}\left(-u_{l} / u_{c}\right)+u_{l}=0, \\
& v_{c} h_{\bar{c}}+v_{\bar{c}}=u_{c}\left(-u_{\bar{c}} / u_{c}\right)+u_{\bar{c}}=0, \\
& v_{c} h_{G}+v_{G}=u_{c}\left(-u_{G} / u_{c}\right)+u_{G}=0 .
\end{aligned}
$$

Therefore, regardless of whether the government is welfarist or non-welfarist, i.e., regardless of whether we maximize (A12) or (A13), the social first-order conditions for $l_{\omega}, \bar{c}$, and $G^{G o v}$ take the same form. By using $h_{l}=-u_{l} / u_{c}=-M R S_{l, c}$ and $h_{G}=-u_{G} / u_{c}=-M R S_{G, c}$, and if we suppress the type indicator $\omega$ for notational convenience, the social first-order conditions for $l_{\omega}$ and $G^{G o v}$ (if $G^{G o v}>0$ ) can be written as follows:

$$
\begin{gathered}
w+M R S_{l, c}=-\frac{\theta u_{c} M R S_{l, c}}{\lambda f(w) w}\left(1+\varepsilon_{l}^{l c}\right)+\frac{\theta^{b} u_{c} M R S_{l, c}}{\lambda f(\omega) c} \varepsilon_{c}^{l c}-\frac{\eta}{\lambda} M R S_{l, c}=0 \\
\int_{\Omega} M R S_{G c} f(\omega) d \omega\left(1+\frac{\eta}{\lambda}\right)+\int_{\Omega} \frac{\theta^{w} u_{c} M R S_{G, c}}{\lambda f(\omega) w} \varepsilon_{l}^{G c} f(\omega) d \omega-\int_{\Omega} \frac{\theta^{b} u_{c} M R S_{G, c}}{\lambda f(\omega) c} \varepsilon_{c}^{G c} f(\omega) d \omega=1 \text {.(A15) }
\end{gathered}
$$

As we did in the proof of Propositions 3, we can derive an expression for $\eta / \lambda$ from the social first-order condition for $\bar{c}$. By using $h_{\bar{c}}=-u_{\bar{c}} / u_{c}=-M R S_{\bar{c}, c}$, the social first-order condition for $\bar{c}$ can be written as

$$
\frac{\eta}{\lambda}\left(1+\int_{\Omega} \frac{u_{\bar{c}}}{u_{c}} f(\omega) d \omega\right)=\frac{1}{\lambda} \int_{\Omega} \theta^{w} u_{c} \frac{\partial \alpha}{\partial l} \frac{l}{w} d \omega-\frac{1}{\lambda} \int_{\Omega} \theta_{\omega}^{b} u_{c} \frac{\partial \alpha}{\partial c} d \omega-\int_{\Omega} \frac{u_{\bar{c}}}{u_{c}} f(\omega) d \omega .
$$

Define

$$
\begin{gathered}
\bar{\alpha}=-\int_{\Omega} \frac{u_{\bar{c}}}{u_{c}} f(\omega) d \omega=\int_{\Omega} \alpha f(\omega) d \omega \\
\alpha^{D}=\frac{1}{\lambda}\left(\int_{\Omega} \theta^{w} u_{c} \frac{\partial \alpha}{\partial l} \frac{l}{w} d \omega-\int_{\Omega} \theta^{b} u_{c} \frac{\partial \alpha}{\partial c} d \omega\right)=\int_{\Omega} \frac{\theta^{w} u_{c} \alpha}{\lambda f(\omega) w} \varepsilon_{l}^{\alpha} f(\omega) d \omega-\int_{\Omega} \frac{\theta^{b} u_{c} \alpha}{\lambda f(\omega) c} \varepsilon_{c}^{\alpha} d \omega .
\end{gathered}
$$

Substituting into equation (A16) gives

$$
\frac{\eta}{\lambda}=\frac{\bar{\alpha}+\alpha^{D}}{1-\bar{\alpha}}
$$

Next, substitute equation (A17) into equations (A14) and (A15), and use the private firstorder condition, $w+M R S_{l, c}=-w T_{y}$, in equation (A14). Then, by using the notations

$$
\begin{aligned}
B_{w, b}^{w} C_{w, b}^{w} & =\frac{\theta_{w, b}^{w} u_{c(w, b)}}{\Gamma_{w, b}^{w} \lambda w f(w, b)}, \\
B_{w, b}^{b} C_{w, b}^{b} & =\frac{\theta_{w, b}^{b} u_{c(w, b)}}{\left(1-\Gamma_{w, b}^{w}\right) \lambda c f(w, b)},
\end{aligned}
$$


we obtain the policy rules for marginal income taxation and public good provision in (i) and (ii) of Proposition 4.

Let us then turn to the marginal tax treatment of charitable giving under welfarism. Suppose first that $G^{G o v}>0$ at the social optimum. By using $h_{g}=-u_{g} / u_{c}=-M R S_{g, c}$ and $h_{\bar{g}}=-u_{\bar{g}} / u_{c}=-M R S_{\bar{g}, c}=\beta M R S_{g, c}$, we can derive the following social first-order conditions for $g_{\omega}$ and $\bar{g}$ from equation (A12):

$$
\begin{aligned}
& \operatorname{MRS}_{g, c}\left(1+\frac{\eta}{\lambda}\right)=-\frac{\theta^{w} u_{c}}{\lambda f(\omega)} \frac{\partial M R S_{g, c}}{\partial l} \frac{l}{w}+\frac{\theta^{b} u_{c}}{\lambda f(\omega)} \frac{\partial M R S_{g, c}}{\partial c}+\mu+\frac{\zeta}{\lambda}-\frac{\phi}{\lambda f(\omega)} \\
& \frac{\zeta}{\lambda}=\frac{1}{\lambda} \int_{\Omega} \theta_{\omega}^{w} u_{c}\left(\frac{\partial \beta}{\partial l} M R S_{g, c}+\beta \frac{\partial M R S_{g, c}}{\partial l}\right) \frac{l}{w} d \omega \\
& -\frac{1}{\lambda} \int_{\Omega} \theta_{\omega}^{b} u_{c}\left(\frac{\partial \beta}{\partial c} M R S_{g, c}+\beta \frac{\partial M R S_{g, c}}{\partial c}\right) d \omega+\left(1+\frac{\eta}{\lambda}\right) \int_{\Omega} \beta M R S_{g, c} f(\omega) d \omega
\end{aligned}
$$

where we have used

$$
\frac{\partial M R S_{\bar{g}, c}}{\partial l}=-\frac{\partial \beta}{\partial l} M R S_{g, c}-\beta \frac{\partial M R S_{g, c}}{\partial l} \text { and } \frac{\partial M R S_{\bar{g}, c}}{\partial c}=-\frac{\partial \beta}{\partial c} M R S_{g, c}-\beta \frac{\partial M R S_{g, c}}{\partial c} .
$$

Substituting equation (A20) into the final row of equation (A21) and rearranging gives

$$
\begin{aligned}
\frac{\zeta}{\lambda} & =\frac{\bar{\beta} \mu}{1-\bar{\beta}}+\frac{1}{1-\bar{\beta}} \frac{1}{\lambda}\left(\int_{\Omega} \theta_{\omega}^{w} u_{g} \frac{\partial \beta}{\partial l} \frac{l}{w} d \omega-\int_{\Omega} \theta_{\omega}^{b} u_{g} \frac{\partial \beta}{\partial c} d \omega\right)-\frac{1}{1-\bar{\beta}} \frac{1}{\lambda} \int_{\Omega} \beta_{\omega} \phi_{\omega} d \omega \\
& =\frac{\bar{\beta} \mu+\beta^{D}-\beta^{n o n}}{1-\bar{\beta}}
\end{aligned}
$$

where

$$
\begin{aligned}
\bar{\beta} & =\int_{\Omega} \beta_{\omega} f(\omega) d \omega, \\
\beta^{D} & =\frac{1}{\lambda}\left(\int_{\Omega} \theta_{\omega}^{w} u_{g} \frac{\partial \beta}{\partial l} \frac{l}{w} d \omega-\int_{\Omega} \theta_{\omega}^{b} u_{g} \frac{\partial \beta}{\partial c} d \omega\right) \\
& =\int_{\Omega} \frac{\theta_{\omega}^{w} u_{g} \beta_{w}}{\lambda f(\omega) w} \varepsilon_{l(\omega)}^{\beta} f(\omega) d \omega-\int_{\Omega} \frac{\theta_{\omega}^{b} u_{g} \beta_{w}}{\lambda f(\omega) c} \varepsilon_{c(w)}^{\beta} f(\omega) d \omega \\
\beta^{n o n} & =\frac{1}{\lambda} \int_{\Omega} \beta_{\omega} \phi_{\omega} d \omega .
\end{aligned}
$$

By using the elasticities $\varepsilon_{l}^{g c}$ and $\varepsilon_{c}^{g c}$, equation (A20) can be rewritten to read

$$
\operatorname{MRS}_{g, c}\left(1+\frac{\eta}{\lambda}\right)=-\frac{\theta^{w} u_{c} M R S_{g, c}}{\lambda f(\omega) w} \varepsilon_{l}^{g c}+\frac{\theta^{b} u_{c} M R S_{g, c}}{\lambda f(\omega) c} \varepsilon_{c}^{g c}+\mu+\frac{\zeta}{\lambda}-\frac{\phi}{\lambda f(\omega)} .
$$

Substitute the expression for $\zeta / \lambda$ in equation (A22) into equation (A23) and use the short 
notations in equations (A18) and (A19). Finally, using the private first-order condition, $M R S_{g, c}=1+T_{g}$ gives the policy rule in (iii).

If $G^{G o v}=0$ at the social optimum, the analogues of equations (A20) and (A22) become

$$
\begin{gathered}
\operatorname{MRS}_{g, c}\left(1+\frac{\eta}{\lambda}\right)=\mu-\frac{\theta^{w} u_{c}}{\lambda f(\omega)} \frac{\partial M R S_{g, c}}{\partial l} \frac{l}{w}+\frac{\theta^{b} u_{c}}{\lambda f(\omega)} \frac{\partial M R S_{g, c}}{\partial c}+\frac{\zeta}{\lambda}+(1-\mu) S^{0} \\
\frac{\zeta}{\lambda}=\frac{\bar{\beta}\left(\mu+(1-\mu) S^{0}\right)}{1-\bar{\beta}}+\frac{1}{1-\bar{\beta}} \frac{1}{\lambda}\left(\int_{\Omega} \theta_{\omega}^{w} u_{g} \frac{\partial \beta}{\partial l} \frac{l}{w} d \omega-\int_{\Omega} \theta_{\omega}^{b} u_{g} \frac{\partial \beta}{\partial c} d \omega\right)-\frac{1}{1-\bar{\beta}} \frac{1}{\lambda} \int_{\Omega} \beta_{\omega} \phi_{\omega} d \omega \\
=\frac{\bar{\beta}\left(\mu+(1-\mu) S^{0}\right)+\beta^{D}-\beta^{n o n}}{1-\bar{\beta}}
\end{gathered}
$$

where $S^{0}=\frac{\Upsilon}{\lambda}=1-\left(\int_{\Omega} M R S_{G c}\left(\frac{1+\alpha^{D}}{1-\bar{\alpha}}+\frac{\theta^{w} u_{c} \varepsilon_{l}^{G c}}{\lambda f(\omega) w}-\frac{\theta^{b} u_{c} \varepsilon_{c}^{G c}}{\lambda f(\omega) c}\right) f(\omega) d \omega\right)_{G^{G o v}=0}$.

Combining equations (A24) and (A25) in the same way as above gives the policy rule in (iv).

Under non-welfarism, the procedure is the same, except that the social first-order conditions are now derived from equation (A13). We can differentiate equation (A13) with respect to $g_{\omega}$ and $\bar{g}$ in order to derive the following analogues to equations (A20) and (A22) when $G^{\text {Gov }}>0$ at the social optimum:

$$
\begin{aligned}
\operatorname{MRS}_{g, c}\left(1+\frac{\eta}{\lambda}\right)=\mu-\frac{\theta^{w} u_{c}}{\lambda f(\omega)} \frac{\partial M R S_{g, c}}{\partial l} \frac{l}{w}+\frac{\theta^{b} u_{c}}{\lambda f(\omega)} \frac{\partial M R S_{g, c}}{\partial c}+\frac{\zeta}{\lambda}-\frac{\phi}{\lambda f \omega)}+\frac{\psi^{\prime}(u) u_{c}}{\lambda} M R S_{g, c} \\
\frac{\zeta}{\lambda}=\frac{\bar{\beta} \mu}{1-\bar{\beta}}+\frac{1}{1-\bar{\beta}} \frac{1}{\lambda}\left(\int_{\Omega} \theta_{\omega}^{w} u_{g} \frac{\partial \beta}{\partial l} \frac{l}{w} d \omega-\int_{\Omega} \theta_{\omega}^{b} u_{g} \frac{\partial \beta}{\partial c} d \omega\right)-\frac{1}{1-\bar{\beta}} \frac{1}{\lambda} \int_{\Omega} \beta_{\omega} \phi_{\omega} d \omega \\
=\frac{\bar{\beta} \mu+\beta^{D}-\beta^{n o n}}{1-\bar{\beta}}
\end{aligned}
$$

By substituting equation (A27) into equation (A26), we obtain the policy rule in (v). If $G^{G o v}=0$ at the social optimum, the procedure is again analogous to that under welfarism, and implies that an additional term proportional to $S^{0}$ will appear in the social first-order condition for $g_{\omega}$ and in the expression for $\zeta / \lambda$.

\section{Numerical Illustration: supplement}

Table 1 presents the before-tax income, $y$, disposable income, $y-T(y, g)$, and charitable giving, $g$, for the $10^{\text {th }}, 30^{\text {th }}, 50^{\text {th }}, 70^{\text {th }}, 90^{\text {th }}$, and $95^{\text {th }}$ income percentiles. The parameters are set according to the numerical reference scenario. 
Table A1. Before-tax income, disposable income, and charitable giving

\begin{tabular}{lllllll}
\hline \multicolumn{7}{c}{ Reference scenario with no positional concerns; $\alpha=0, \beta=0$} \\
\hline$F(w)$ & $y=w l$ & $y-T(y, g)$ & $g$ & $y=w l$ & $y-T(y, g)$ & $g$ \\
\hline \multicolumn{7}{c}{ Welfarist Government } \\
\hline 0.10 & 23,496 & 28,801 & 0.0 & 23,648 & 28,988 & 0.0 \\
0.30 & 44,339 & 42,065 & 0.0 & 44,626 & 42,338 & 0.0 \\
0.50 & 61,392 & 54,571 & 2.1 & 61,409 & 53,781 & 0.0 \\
0.70 & 82,614 & 70,487 & 4.8 & 82,387 & 67,893 & 0,0 \\
0.90 & 126,953 & 102,699 & 7.7 & 125,870 & 97,263 & 0.0 \\
0.95 & 158,407 & 125,058 & 8.8 & 157,528 & 118,241 & 1.3 \\
\hline \multicolumn{7}{c}{ Non-welfarist Government } \\
\hline 0.10 & 23,625 & 35,437 & 0.0 & 23,649 & 35,473 & 0.0 \\
0.30 & 44,583 & 46,107 & 0.0 & 44,628 & 46,154 & 0.0 \\
0.50 & 61,730 & 55,252 & 0.0 & 61,411 & 55,308 & 0.0 \\
0.70 & 82,687 & 67,826 & 2.2 & 82,390 & 66,751 & 0.0 \\
0.90 & 127,270 & 93,738 & 5.3 & 125,873 & 90,019 & 0.0 \\
0.95 & 158,897 & 111,647 & 6.8 & 157,533 & 105,657 & 1.4 \\
\hline
\end{tabular}

Notes: The columns represent the cumulative distribution (ability), before-tax income (US\$), disposable income (US\$), and charitable giving (in percent of disposable income). The per capita contribution to the public good (in percent of median gross income) by the welfarist (non-welfarist) government is $17 \%$ (19\%) in the scenario without positional concerns, while it is $18 \%$ (19\%) in the scenario with positional concerns.

\section{References}

Alpizar, F., F. Carlsson, O. Johansson-Stenman (2005) How Much Do We Care about Absolute versus Relative Income and Consumption? Journal of Economic Behavior and Organization 56, 405-421.

Andreoni, J. (1989) Giving with Impure Altruism: Applications to Charity and Ricardian Equivalence. Journal of Political Economy 97, 1447-1458.

Aronsson, T., O. Johansson-Stenman (2008) When the Joneses' Consumption Hurts: Optimal Public Good Provision and Nonlinear Income Taxation. Journal of Public Economics 92, 986-997.

Aronsson, T., O. Johansson-Stenman (2010) Positional Concerns in an OLG Model: Optimal Labor and Capital Income Taxation. International Economic Review 51, 1071-1095.

Aronsson, T., O. Johansson-Stenman (2018) Paternalism Against Veblen: Optimal Taxation and Non-Respected Preferences for Social Comparisons. American Economic Journal: Economic Policy 10, 39-76.

Aronsson, T., O. Johansson-Stenman, and R. Wendner (2019) Charity as Income Redistribution: A Model with Optimal Taxation, Status, and Social Stigma. Working Paper: Umeå Economic Studies no 961. 
Atkinson, A.B. (1976) The Income Tax Treatment of Charitable Contributions. In: Grieson, R. (Ed.), Public and Urban Economics: Essays in the Honor of William S. Vickrey. D.C. Heath, New York.

Atkinson, A. B., J. E. Stiglitz (1976) The Design of Tax Structure: Direct versus Indirect Taxation. Journal of Public Economics 6, 55-75.

Blanchflower, D.G., A.J. Oswald (2004) Well-Being Over Time in Britain and the USA. Journal of Public Economics 88, 1359-1386.

Bergstrom, T., L. Blume, H. Varian (1986) On the Private Provision of Public Goods. Journal of Public Economics 29, 25-49.

Blumkin, T., E. Sadka (2007) A case for taxing charitable donations. Journal of Public Economics 91, 1555-1564.

Boadway, R., M. Keen (1993) Public Goods, Self-Selection and Optimal Income Taxation. International Economic Review 34, 463-478.

Boskin, M.J., E. Sheshinski (1978) Individual Welfare Depends Upon Relative Income. Quarterly Journal of Economics 92, 589-601.

Carlsson, F., O. Johansson-Stenman, P. Martinsson (2007) Do You Enjoy Having More Than Others? Survey Evidence of Positional Goods. Economica 74, 586-598.

Christiansen, V. (1981) Evaluation of Public Projects under Optimal Taxation. Review of Economic Studies 48, 447-457.

Clark, A., C. Senik (2010) Who Compares to Whom? The Anatomy of Income Comparisons in Europe. Economic Journal 120, 573-594.

Cremer, H., P. Pestieau, J-C. Rochet (2001) Direct Versus Indirect Taxation: The Design of the Tax Structure Revisited. International Economic Review 42, 781-800.

DellaVigna, S., J. List, U. Malmendier (2012) Testing for Altruism and Social Pressure in Charitable Giving. Quarterly Journal of Economics 127, 1-56.

Diamond, P. (1980) Income Taxation with Fixed Hours of Work. Journal of Public Economics 13, 101-110.

Diamond, P. (1998) Optimal Income Taxation: An Example with a U-Shaped Pattern of Optimal Marginal Tax Rates. American Economic Review 88, 83-95.

Diamond, P. (2006) Optimal Tax Treatment of Private Contributions for Public Goods with and Without Warm-Glow Preferences. Journal of Public Economics 90, 897-919.

Dupor, B., W.F. Liu (2003) Jealousy and Overconsumption. American Economic Review 93, 423-428. 
Easterlin, R.A. (2001) Income and Happiness: Towards a Unified Theory. Economic Journal $111,465-484$.

Eckerstorfer, P., R. Wendner (2013) Asymmetric and Non-Atmospheric Consumption Externalities, and Efficient Consumption Taxation. Journal of Public Economics 106, $42-56$.

Fack, G., C. Laindais, eds., (2012) Charitable Giving and Tax Policy: A Historical and Comparative Perspective. Conference Volume, CEPR/CEPREMAP Conference on Altruism and Charitable Giving held in May 2012, Paris School of Economics.

Feldstein, M. (1980) A Contribution to the Theory of Tax Expenditures: The Case of Charitable Giving. In: Aaron, H. J., and M. J. Boskin (Eds.), The Economics of Taxation, Essays in Honor of Joseph Peckman, 99-122. Brookings Institution, Washington, D.C.

Ferrer-i-Carbonell, A. (2005) Income and Well-being: An Empirical Analysis of the Comparison Income Effect. Journal Public Economics 89, 997-1019.

Giving USA (2020), The Annual Report on Philanthropy for the Year 2019, a publication of Giving USA Foundation, 2020, Indiana University Lilly Family School of Philanthropy.

Glazer, A., K. Konrad (1996) A Signaling Explanation for Charity. American Economic Review 86, 1019-1028.

Golosov, M., A. Tsyvinski, N. Werquin (2014) Dynamic Tax Reforms. NBER Working Papers 20780.

Harbaugh, W. (1998) The Prestige Motive for Making Charitable Transfers. American Economic Review 88, 277-282.

Harsanyi, J. (1982) Morality and the Theory of Rational Behavior. In Utilitarianism and Beyond, edited by Sen, A. and Williams, B. Cambridge: Cambridge University Press.

Jacobs, B., R. Boadway (2014) Optimal Linear Commodity Taxation under Optimal Nonlinear Income Taxation. Journal of Public Economics 117, 201-210.

Johansson-Stenman, O., F. Carlsson, D. Daruvala (2002) Measuring Future Grandparents' Preferences for Equality and Relative Standing. Economic Journal 112, 362-383.

Kanbur, R., M. Tuomala (2013) Relativity, Inequality and Optimal Nonlinear Income Taxation. International Economic Review 54, 1199-1217.

Kaplow, L. (1995) A note on subsidizing gifts. Journal of Public Economics 58, 469-477.

Kaplow, L. (1998) Tax Policy and Gifts. American Economic Review, Papers and Proceedings 88, 283-288. 
Kaplow, L., S. Shavell (2001) Any Non-welfarist Method of Policy Assessment Violates the Pareto Principle. Journal of Political Economy 109, 281-286.

Kleven, H. J., C. T. Kreiner, E. Saez (2009) The Optimal Income Taxation of Couples. Econometrica 77, 537-560.

Lehmann, E., S. Renes, K. Spiritus, F. Zoutman (2020) Optimal Taxation with Multiple Incomes and Types. Mimeo.

Ljungqvist, L., H. Uhlig (2000) Tax Policy and Aggregate Demand Management Under Catching Up with the Joneses. American Economic Review 90, 356-366.

Mirrlees, J. (1971) An Exploration in the Theory of Optimal Income Taxation. Review of Economic Studies 38, 175-208.

Mirrlees, J. (1986) The Theory of Optimal Taxation. In K. J. Arrow and M.D. Intriligator, eds., Handbook of Mathematical Economics, Vol. 3, Elsevier, chapter 24, 1197-1249.

Oswald, A. (1983) Altruism, Jealousy and the Theory of Optimal Non-Linear Taxation. Journal of Public Economics 20, 77-87.

Renes, R., F. Zoutman (2017) As Easy as ABC? Multidimensional Screening in Public Finance. CESifo Working Paper No. 6301.

Runciman, W.G. (1966) Relative Deprivation and Social Justice. London: Routledge and Kegan Paul.

Saez, E. (2001) Using Elasticities to Derive Optimal Income Tax Rates. Review of Economic Studies 68, 205-229.

Saez, E. (2002) The Desirability of Commodity Taxation under Non-Linear Income Taxation and Heterogeneous Tastes. Journal of Public Economics 83, 217-230.

Saez, E., (2004) The Optimal Treatment of Tax Expenditures. Journal of Public Economics $88,2657-2684$.

Solnick, S., D. Hemenway (2005) Are Positional Concerns Stronger in Some Domains than in Others? American Economic Review, Papers and Proceedings 45, 147-151.

Tuomala, M. (2016) Optimal Redistributive Taxation. Oxford: Oxford University Press.

Veblen, T. (1899) The Theory of the Leisure Class: An Economic Study in the Evolution of Institutions. New York: Macmillan.

Warr, P. (1982). Pareto Optimal Redistribution and Private Charity. Journal of Public Economics 19, 131-138.

Wendner, R., L.H. Goulder (2008) Status Effects, Public Goods Provision, and the Excess Burden. Journal of Public Economics 92, 1968-1985. 